Article

\title{
An Improved Parameterization for Retrieving Clear-Sky Downward Longwave Radiation from Satellite Thermal Infrared Data
}

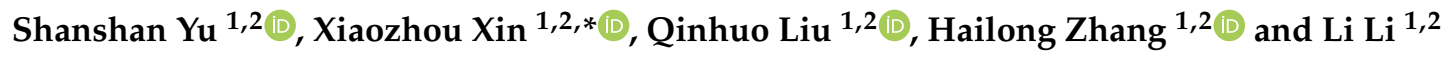 \\ 1 State Key Laboratory of Remote Sensing Science, Jointly Sponsored by Institute of Remote Sensing and \\ Digital Earth of Chinese Academy of Sciences and Beijing Normal University, Beijing 100101, China; \\ yuss@radi.ac.cn (S.Y.); liuqh@radi.ac.cn (Q.L.); zhlnjnu@163.com (H.Z.); lili3982@radi.ac.cn (L.L.) \\ 2 Joint Center for Global Change Studies (JCGCS), Beijing 100875, China \\ * Correspondence: xinxz@radi.ac.cn; Tel.: +86-10-6487-9382
}

Received: 21 January 2019; Accepted: 14 February 2019; Published: 19 February 2019

\begin{abstract}
Surface downward longwave radiation (DLR) is a crucial component in Earth's surface energy balance. Yu et al. (2013) developed a parameterization for retrieving clear-sky DLR at high spatial resolution by combined use of satellite thermal infrared (TIR) data and column integrated water vapor (IWV). We extended the Yu2013 parameterization to Moderate Resolution Imaging Spectroradiometer (MODIS) data based on atmospheric radiative simulation, and we modified the parameterization to decrease the systematic negative biases at large IWVs. The new parameterization improved DLR accuracy by 1.9 to $3.1 \mathrm{~W} / \mathrm{m}^{2}$ for IWV $\geq 3 \mathrm{~cm}$ compared to the Yu2013 algorithm. We also compared the new parameterization with four algorithms, including two based on Top-of-Atmosphere (TOA) radiance and two using near-surface meteorological parameters and water vapor. The algorithms were first evaluated using simulated data and then applied to MODIS data and validated using surface measurements at 14 stations around the globe. The results suggest that the new parameterization outperforms the TOA-radiance based algorithms in the regions where ground temperature is substantially different (enough that the difference between them is as large as $20 \mathrm{~K}$ ) from skin air temperature. The parameterization also works well at high elevations where atmospheric parameter-based algorithms often have large biases. Furthermore, comparing different sources of atmospheric input data, we found that using the parameters interpolated from atmospheric reanalysis data improved the DLR estimation by $7.8 \mathrm{~W} / \mathrm{m}^{2}$ for the new parameterization and $19.1 \mathrm{~W} / \mathrm{m}^{2}$ for other algorithms at high-altitude sites, as compared to MODIS atmospheric products.
\end{abstract}

Keywords: parameterization; brightness temperature; water vapor content; ground-air temperature difference; MODIS; downward longwave radiation

\section{Introduction}

The surface downward longwave radiation (DLR) is radiative flux density reaching the surface in the thermal infrared (TIR) part of the electromagnetic spectrum $(4-100 \mu \mathrm{m})$ and represents a key component in land-atmosphere interactions. DLR is related to the downward radiance at the Earth's surface as [1]:

$$
D L R=2 \pi \int_{v_{1}}^{v_{2}} \int_{0}^{1} I_{v}(z=0,-\mu) \mu d \mu d v,
$$


where $I_{v}(z=0,-\mu)$ is the spectral radiance at the surface at a given local zenith angle $\theta$ and $\mu=\cos (\theta)$ and $v$ is the wavenumber. Under cloud-free conditions, multiple scatter can be omitted, thus spectral radiance can be expressed as:

$$
I_{\lambda}(z=0,-\mu)=\int_{0}^{z_{t}} B_{v}\left(z^{\prime}\right) \frac{\partial T_{v}\left(0, z^{\prime} ;-\mu\right)}{\partial z^{\prime}} d z^{\prime}
$$

where $z_{t}$ is the top of atmosphere, $B_{v}\left(z^{\prime}\right)$ is the Planck function evaluated with the temperature at level $z^{\prime}$, and $T_{v}\left(0, z^{\prime} ;-\mu\right)$ is the monochromatic transmittance from surface to height $z^{\prime}$.

A global, long-term DLR database is needed for studies of surface energy budget and global climate change [2-5]. Although surface radiation fluxes can be obtained by field measurement, their sparsity makes downward radiation estimation difficult over larger regions or regions without in-situ measurement stations, while remote sensing provides more complete spatial coverage.

Surface DLR results from atmospheric absorption, emission, and scattering within the entire atmospheric column. If detailed atmospheric information is available, including vertical profiles of temperature and humidity, ozone and other trace gases, aerosols, as well as cloud physical properties such as cloud height and cloud temperature, DLR can be accurately calculated by detailed radiative-transfer (RT) modeling. This method has been applied to data from the TIROS Operational Vertical Sounder (TOVS) of National Oceanic and Atmospheric Administration (NOAA) satellites [6], International Satellite Cloud Climatology Project (ISCCP, [7]), and Clouds and the Earth's Radiant Energy System (CERES, [8]).

Considering that RT methods require extensive computation and multiple input parameters that are unavailable for many satellites, researchers developed more practical algorithms, including empirical and parameterized algorithms. Because the major part of surface DLR originates from the first few hundred meters of the atmospheric layer above the earth surface under clear sky conditions [9], the empirical algorithms establish empirical relationships between clear-sky DLR and meteorological parameters such as near-surface air temperature and humidity [10-13]. Such algorithms have been applied to the Meteosat series [14-16], Moderate Resolution Imaging Spectroradiometer (MODIS, [17,18]), Geostationary Operational Environmental Satellite (GOES, [19]), and CERES data [20]. Empirical algorithms are usually developed using in-situ observations from certain surface sites and must be adjusted for other locations, which makes them unsuitable for use at larger scales. The parameterized algorithms express DLR as a function of key atmospheric parameters, and most of these algorithms determine the relationship between DLR and input parameters through extensive radiative-transfer model calculation and statistical regression. Gupta et al. [21,22] defined clear-sky DLR in terms of atmospheric effective temperature and column-integrated water vapor (IWV). Inamdar and Ramanathan [23] established a relationship between clear-sky DLR and satellite-retrieved parameters, including top-of-atmosphere (TOA) outgoing longwave radiation, IWV, land surface temperature, and near-surface air temperature. Zhou et al. [24,25] determined clear-sky DLR from surface upward longwave radiation and IWV.

Meteorological data used by the last two types of algorithms come from either atmospheric reanalysis datasets or satellite retrieval products, thus algorithm error is affected by the retrieval accuracy of atmospheric parameters [1]. In addition, atmospheric data are often at coarse spatial resolution $\left(\geq 1^{\circ}\right)$, which may have large errors when they are directly used at fine scale. Current global radiation products such as ISCCP-FD, Global Energy and Water Cycle Experiment-Surface Radiation Budget (GEWEX-SRB), and CERES-FSW were found to have large errors in high-altitude regions such as the Qinghai-Tibetan Plateau, which were mainly caused by errors in surface air temperature and water vapor content [26-28]. Zhang et al. [29] pointed out that an uncertainty of $\sim 2-4 \mathrm{~K}$ in surface air temperature would induce $\sim 15 \mathrm{~W} / \mathrm{m}^{2}$ of uncertainty in the DLR of ISCCP.

To avoid propagating retrieval errors of satellite-derived atmospheric parameters into final radiation estimates, some researchers have developed hybrid algorithms that use satellite-observed thermal infrared (TIR) data to calculate clear-sky DLR directly. Algorithms for the high-resolution 
infrared spectrometer (HIRS/2) of NOAA [1], MODIS [30-34], and GOES Sounder [35] have been developed during the past two decades. In these algorithms, the DLR is expressed by linear or nonlinear combinations of multispectral infrared radiances or brightness temperature (BT) at the TOA. Because this type of algorithm is not only free from real-time atmospheric and surface information but also can derive DLR at the same spatial resolution as satellite thermal data, it is regarded as a promising trend in radiative flux estimation [32]. However, hybrid models that use TOA radiance or land surface temperature always greatly overestimate DLR during daytime over dry-arid regions where surface skin temperature is significantly higher than near-surface air temperature $[27,30]$.

To overcome the DLR overestimation over dry-arid regions for TOA radiance-based algorithms, Yu et al. [36] (hereafter Yu2013) proposed a correction based on ground minus air temperature difference, denoted as $\delta T_{s, a}$. They developed a parameterization that estimates clear-sky DLR from the BT of Huan Jing InfraRed Scanner (HJ-1B IRS) thermal channel $(10.8 \mu \mathrm{m})$ and the synchronous MODIS water vapor product. They found that taking into account $\delta T_{s, a}$ improved DLR at dry-arid sites. The Yu2013 parameterization provides a new approach to obtaining DLR from satellite TOA data. This algorithm is not restricted to satellites with multispectral infrared channels, such as MODIS, but can also be used for satellites with a single thermal channel, such as Fengyun-2E (FY-2E) and HJ-1B IRS. However, Yu et al. [36] also found obvious negative errors under high IWV values upon validation of the parameterization by a testing dataset that was simulated using a radiative transfer model and global radio-soundings.

The purpose of this paper is to extend Yu2013 parameterization to MODIS data by coefficient reconstruction, taking advantage of the high-quality input data from MODIS to improve the parameterization and decrease the systematic negative biases at high IWV values and to compare the improved parameterization with several other state-of-the-art algorithms with good performance. The rest of the paper is structured as follows: the algorithm introduction, extension, and improvement are described in Section 2. Section 3 assess the improved algorithm based on a simulated dataset and actual MODIS Terra data, respectively. Section 4 further discusses the effect of different sources of atmospheric products on DLR estimation. Section 5 gives the conclusion.

\section{Development of Clear-Sky Algorithm}

\subsection{Clear-Sky DLR Algorithms}

As mentioned in the above section, two types of algorithms have been widely used in DLR estimation, i.e., parameterizations using atmospheric input data and hybrid algorithms using TOA radiance of TIR channels. Table 1 gives four widely used or newly developed algorithms. The algorithms proposed by Zhou et al. [25] and Gupta et al. [22], hereafter referred to as Zhou-Cess and Gupta2010, were used to produce global radiation flux by the CERES Surface Radiation Budget (SRB) team [37]. The two TOA radiance algorithms developed by Tang and Li [30] and Liang and Wang [31], hereafter referred to as Tang-Li and Wang-Liang, define clear-sky DLR by MODIS TOA radiance or brightness temperature. Zhou-Cess, Gupta2010, and Tang-Li algorithms were developed using global distributed atmospheric profiles, whereas the Wang-Liang algorithm was developed based on profiles over the North American continent only.

The Yu2013 parameterization is a hybrid of the two types of algorithms above. This parameterization was developed at the hypothesis that the atmosphere is a grey body, and clear-sky DLR can be written as $\sigma \varepsilon_{a} T_{e}^{4}$, where $\sigma$ is Stefan-Boltzmann constant, $\varepsilon_{\mathrm{a}}$ is effective emissivity of the entire atmospheric column, and $T_{\mathrm{e}}$ is the effective temperature of the atmosphere. Considering that the TOA BT of TIR channels sensitive to near surface (without making atmospheric corrections) has strong correlation with near-surface air temperature $T_{a}[1,15,36]$, which is relevant to the atmospheric effective temperature under a clear sky, BT is used to represent the effective temperature $[1,36]$. Then, the definition of atmospheric effective emissivity should be adjusted when TOA BT substitutes for atmospheric temperature: 


$$
\varepsilon_{k}=\frac{D L R}{\sigma T_{k}^{4}}
$$

where $T_{k}$ is BT of the TIR channel, and subscript $k$ denotes the channel number. Because atmospheric effective emissivity $\varepsilon_{k}$ can be empirically specified as a function of atmospheric IWV by regression analysis $[1,36]$ :

$$
\varepsilon_{k}=a_{0} I W V+a_{1} \sqrt{I W V}+a_{2},
$$

where IWV has units of $\mathrm{cm}$, and $a_{i}(\mathrm{i}=0,2)$ represent coefficients. Therefore, DLR is expressed as:

$$
D L R=\sigma T_{k}^{4}\left(a_{0} I W V+a_{1} \sqrt{I W V}+a_{2}\right)
$$

For the Yu2013 algorithm, $T_{k}$ used the TIR channel of HJ1B/IRS with a center wavelength of $10.8 \mu \mathrm{m}$. The regression coefficients are the look up tables (LUTs) of elevation $\mathrm{H}$, satellite view zenith angle VZA, and $\delta T_{s, a}$, where $\delta T_{s, a}=T_{s}-T_{a}$. For ordinary regions that $T_{s}$ is similar to $T_{a}$, the regression coefficients are be written as $a_{i}=a_{i}(H, \mathrm{VZA})$. For the condition that $T_{s}$ is very distinct from $T_{a}$, such as in arid regions, $a_{i}=a_{i}\left(H, \mathrm{VZA}, \delta T_{s, a}\right)$. The coefficients were regressed using the dataset simulated by the MODerate resolution atmospheric TRANsmission (MODTRAN) radiation model [38] and

\begin{tabular}{|c|c|c|}
\hline Authors & Abbreviation & Algorithm $^{1}$ \\
\hline Zhou et al. [25] & Zhou-Cess & $D L R=a_{0}+a_{1} \cdot S U L W+a_{2} \cdot \ln (1+I W V)+a_{3} \cdot[\ln (1+I W V)]^{2}$ \\
\hline Gupta et al. [22] & Gupta2010 & $\begin{array}{c}D L R=\left(a_{0}+a_{1} V+a_{2} V^{2}+a_{3} V^{3}\right) \cdot T_{e}^{3.7}, V=\ln (10 * I W V) \\
T_{e}=0.60 T_{s}+0.35 T_{1}+0.05 T_{2}\end{array}$ \\
\hline Tang and Li [30] & Tang-Li & $\begin{array}{c}D L R=a_{0}+a_{1} M_{29}+a_{2} M_{34}+a_{3} M_{33}+a_{4} M_{36}+a_{5} M_{28}+ \\
a_{5} M_{28}+a_{6} M_{31}, M_{i}=\pi L_{i}\end{array}$ \\
\hline Wang and Liang [31] & Wang-Liang & $\begin{array}{c}D L R=L_{\text {Tair }}\left(a_{0}+a_{1} L_{27}+a_{2} L_{29}+a_{3} L_{33}+a_{4} L_{34}+b_{1} L_{32} / L_{31}\right. \\
\left.+b_{2} L_{33} / L_{32}+b_{3} L_{28} / L_{31}+c_{1} H\right)\end{array}$ \\
\hline Yu et al. [36] & Yu2013 & $D L R=\sigma T_{k}^{4}\left(a_{0} I W V+a_{1} \sqrt{I W V}+a_{2}\right)$ \\
\hline
\end{tabular}
thermodynamic Initial Guess Retrieval (TIGR) atmospheric profiles [39].

Table 1. Clear-sky downward longwave radiation (DLR) algorithms.

${ }^{1} L_{i}$ is the top-of-atmosphere (TOA) irradiance of channel $i ; a_{i}$ and $b_{i}$ are regression coefficients, SULW is the surface upwelling longwave flux computed using $2-\mathrm{m}$ air temperature $T_{a}$ with an emissivity of unity, integrated water vapor $(I W V)$ is in unit of $\mathrm{cm}, T_{e}$ is effective temperature which computed from the surface skin temperature $T_{s}$ and the mean temperatures of the lowest two atmospheric layers $\left(T_{1}\right.$ and $\left.T_{2}\right)$, and $\mathrm{H}$ is surface elevation.

\subsection{Extension of Yu2013 Parameterization to MODIS}

When extending the Yu2013 algorithm to MODIS satellite data, $T_{k}$ in (5) is replaced by BT of MODIS channel $31\left(T_{31}\right)$ with a central wavelength of $10.8 \mu \mathrm{m}$, thus $\varepsilon_{k}$ is expressed as $\varepsilon_{31}$. As shown in Figure 1, BT has a strong correlation with atmospheric effective temperature, thus the algorithm is feasible for MODIS. The flowchart of algorithm construction is shown in Figure 2. Firstly, DLR and TOA radiance of MODIS channel 31 were simulated by atmospheric radiative transfer model and global profiles. Then, the relationship between DLR and MODIS $T_{31}$ was derived by regression analysis-actually, the relationship between $\varepsilon_{31}$ and IWV was derived. Finally, the algorithm was validated using simulated data and actual data.

\subsubsection{Training and Testing Datasets Construction}

In order to adequately cover atmospheric variations, two global atmospheric profile databases were used to simulate the training dataset. The atmospheric profile database TIGR2002 of the previous study was used [36]. TIGR2002 includes 2311 atmospheric profiles of temperature, relative humidity, and ozone at 40 fixed pressure levels from 1013 to $0.05 \mathrm{hPa}$. However, TIGR2002 lacks the profiles with high IWV [36]. Therefore, a database of 13,495 profiles generated by Chevallier et al. [40] was also used. These profiles were sampled from European Centre for Medium-Range Weather Forecast (ECMWF) 40-year re-analyses, which are globally distributed and representative of a wide range of 
atmospheric conditions. The ECMWF profiles include temperature, relative humidity, and ozone in 60 fixed pressure levels from 1013 to $0.1 \mathrm{hPa}$. We converted the ECMWF profiles to the same pressure levels as TIGR2002 using the dataset self-contained program. Because only clear-sky conditions were considered, profiles with relative humidity $<85 \%$ in each layer were selected. Finally, 875 TIGR2002 and 7730 ECMWF profiles were used in the simulation.

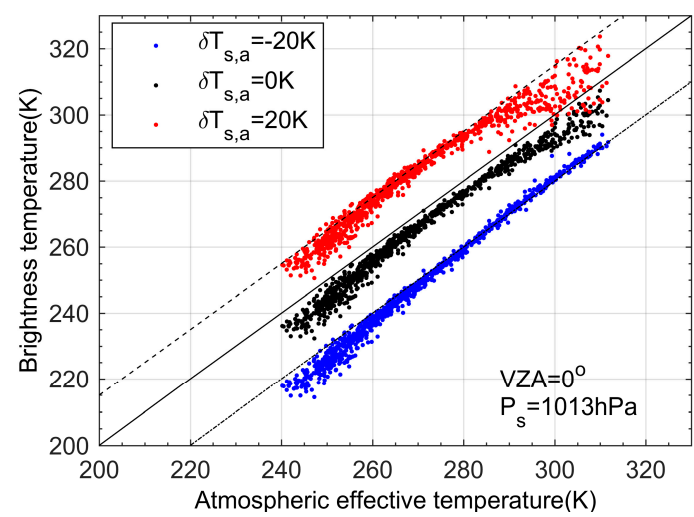

Figure 1. Brightness temperature of Moderate Resolution Imaging Spectroradiometer (MODIS) channel 31 versus atmospheric effective temperature for various $\delta T_{s, a}$ values. Atmospheric effective temperature was defined by the DLR and atmospheric effective emissivity that was simulated using MODTRAN and 875 TIGR2002 profiles.

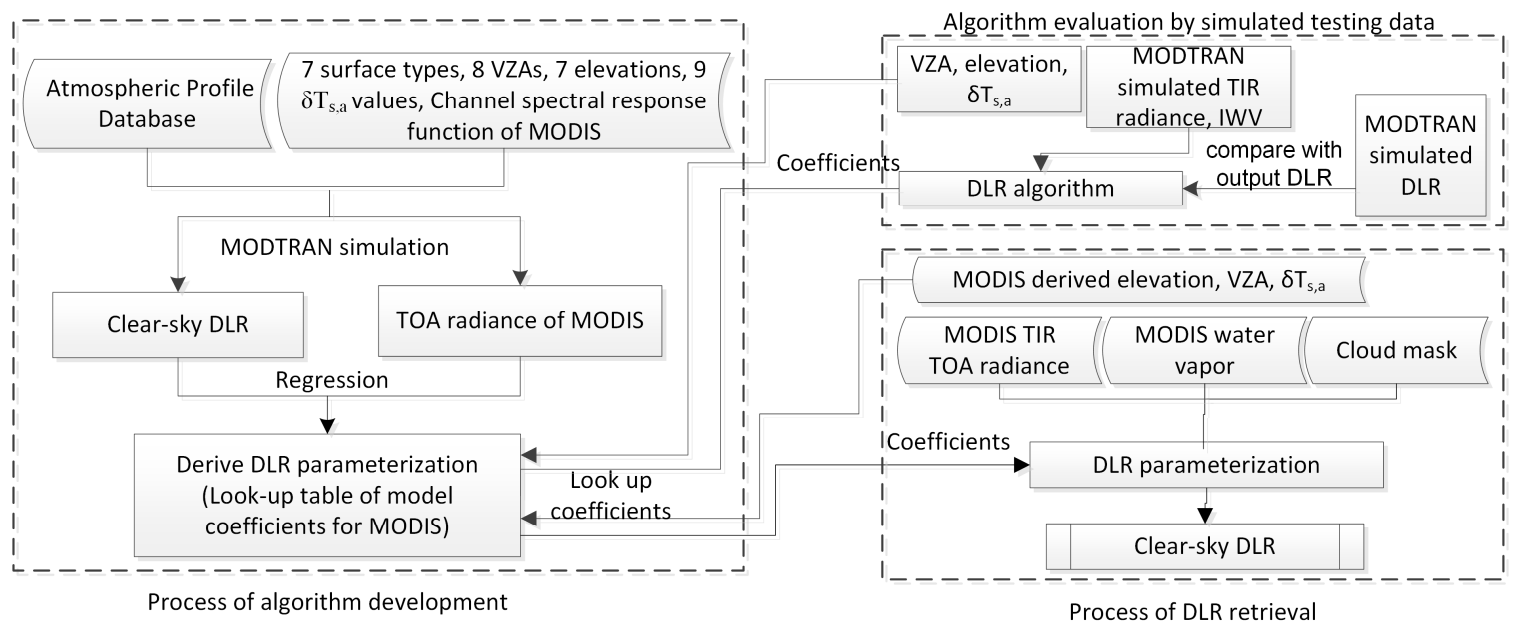

Figure 2. Flowchart of DLR modeling process and DLR derivation.

For each atmospheric profile, the DLR, TOA radiance, and BT of MODIS thermal channels were simulated for various surface types, viewing angles, elevations, and $\delta T_{s, a}$. Version 4.0 of the MODTRAN radiation model was used for simulation. Downward surface radiances at nineteen different zenith angles $\left(0^{\circ}\right.$ to $85^{\circ}$ at $5^{\circ}$ interval, and $\left.89^{\circ}\right)$ were computed for wave numbers ranging between 100 and $3333 \mathrm{~cm}^{-1}$ at a resolution of $1 \mathrm{~cm}^{-1}$. Such values were then integrated to obtain the total DLR according to Equation (1). The model was configured to use ozone and trace gases from a climatological data set and the "Rural" aerosol with horizontal meteorological visible thickness $23 \mathrm{~km}$, all available from MODTRAN. Seven surface types (conifer, dry grass, sea water, fine snow, wetland, concrete, and soil) with distinctly different emissivity spectra, seven elevations, eight VZA, and nine $\delta T_{s, a}$ values were used to simulate TOA radiance and brightness temperature. Surface emissivity spectra were from the ASTER spectral library, and their spectral emissivity are described in Figure 3. To obtain atmospheric profiles at various elevations, profiles from 40 to 34 layers were used, and average elevations of the lowest seven layers were $0.002,0.454,0.934,1.410,1.885,2.670$, and $3.511 \mathrm{~km}$. 
The VZA varied from $0^{\circ}$ to $70^{\circ}$ at a $10^{\circ}$ interval. $T_{s}$ was assumed to be different from $T_{a}$, and the $\delta T_{s, a}$ was between $-20 \mathrm{~K}$ and $20 \mathrm{~K}$ at $5 \mathrm{~K}$ intervals. Knowing DLR and BT, $\varepsilon_{31}$ defined by BT were calculated using Equation (3). IWV for each condition was calculated by MODTRAN directly.

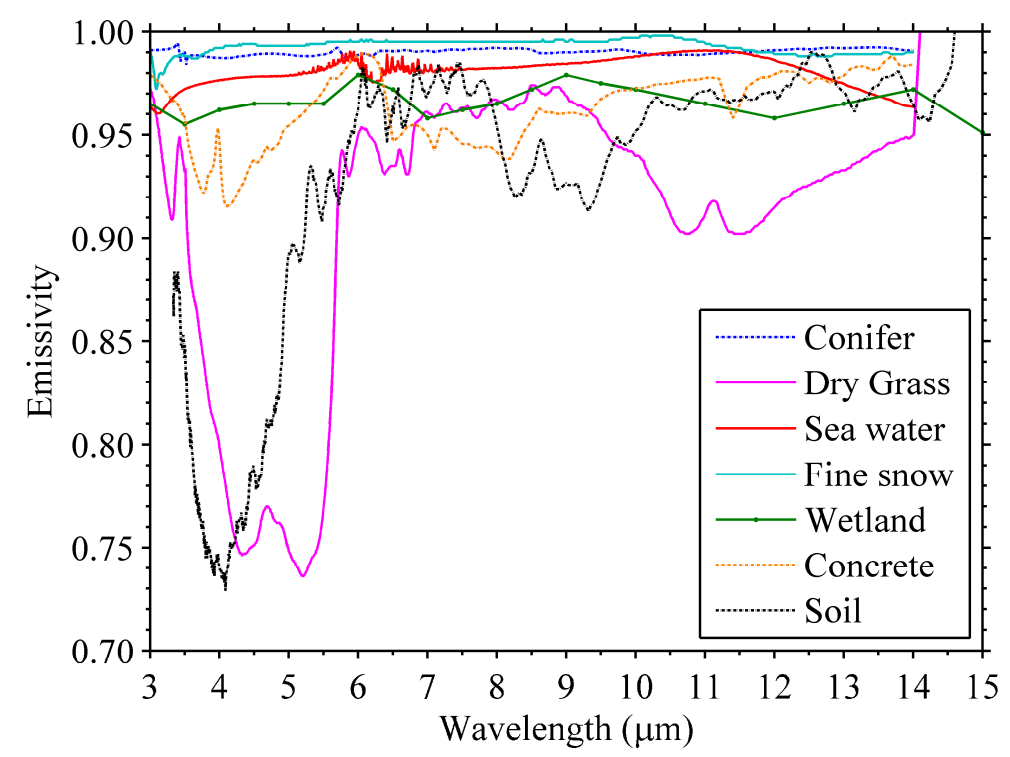

Figure 3. Spectral emissivity curves of seven surface types from ASTER used in MODTRAN simulation.

The testing dataset was used to evaluate whether the new algorithm was appropriate under various atmospheric conditions and to quantify algorithm accuracy under error-free conditions of the input parameters. A global, cloud-free atmospheric profile database, Cloudless Land Atmosphere Radiosounding (CLAR, [41]), was used. CLAR contains 382 radiosoundings taken at uniformly distributed meteorological stations and has a wide range of temperature, humidity, and elevation. Thus, the database can serve as an ideal testing dataset for accuracy evaluation. The testing dataset was generated using the same method as the training dataset except that only these atmospheric profiles at the surface elevation were used, and the ozone was from the climatological data set provided by MODTRAN.

\subsubsection{Improvement of DLR Underestimation at High Water Vapor Content}

Yu et al. [36] found that DLRs predicted by Equation (5) had increasing negative errors with IWV when IWV was large. The underestimation was caused by a significant underestimation of atmospheric emissivity at large IWV, as shown by the fit1 line of Figure 4a. Adding a large number of profiles with large IWV to derive the coefficients can obviously decrease the negative errors, but the underestimation persists (Figure $4 \mathrm{~b}$ ).

Considering that the DLR underestimation was caused by underestimation of atmospheric emissivity $\varepsilon_{31}$, we intended to develop a robust formulation of atmospheric emissivity $\varepsilon_{31}$. Water vapor is the most important atmospheric gas contributing to clear-sky DLR, and the variation of other gases (such as $\mathrm{CO}_{2}$ and $\mathrm{O}_{3}$ ) have small effects on DLR [32,34]. Therefore, we used IWV to predict atmospheric emissivity $\varepsilon_{31}$. As shown in Figure 4 , the atmospheric emissivity $\varepsilon_{31}$ increased with atmospheric IWV and then was nearly unchanged when IWV achieved a specific value. By data analysis, we found that using a logarithmic form of IWV predicted the relationship between atmospheric emissivity $\varepsilon_{31}$ and IWV well, which is consistent with the results in previous studies [22,25,42]. Since the logarithmic function decreases very rapidly with decreasing water vapor below $1 \mathrm{~cm}$, replacing $\ln (\mathrm{IWV})$ by $\ln (1+\mathrm{IWV})$ can avoid flux underestimation under low water vapor conditions [25]. Finally, based on the regression result, the emissivity term of Equation (5) is modified to the following form: 


$$
\begin{gathered}
D L R=\sigma T_{31}^{4}\left(a_{0}+a_{1} V+a_{2} V^{2}+a_{3} V^{3}\right) \\
V=\sqrt{\ln (1+I W V)}
\end{gathered}
$$

where $1+I W V$ is used to ensure that $V$ is greater than zero under low water vapor conditions. In Equation (6), $\mathrm{V}$ is expressed by $\sqrt{\ln (1+I W V})$ rather than $\ln (1+I W V)$ because DLR is overestimated at very large IWV when using $\ln (1+\mathrm{IWV})$ (as shown in Figure $4 a)$. Figure 4 compares atmospheric emissivity $\varepsilon_{31}$ fitted from three different formulations. Using $\sqrt{I W V}$ or $\ln (1+I W V)$ will underestimate or overestimate the atmospheric emissivity $\varepsilon_{31}$ at very large IWV, especially when the number of training profiles is small (Figure 4a). On the contrary, using $\sqrt{\ln (1+I W V})$ produces much better results than the two former formulations, and the result is not restricted by sample number.
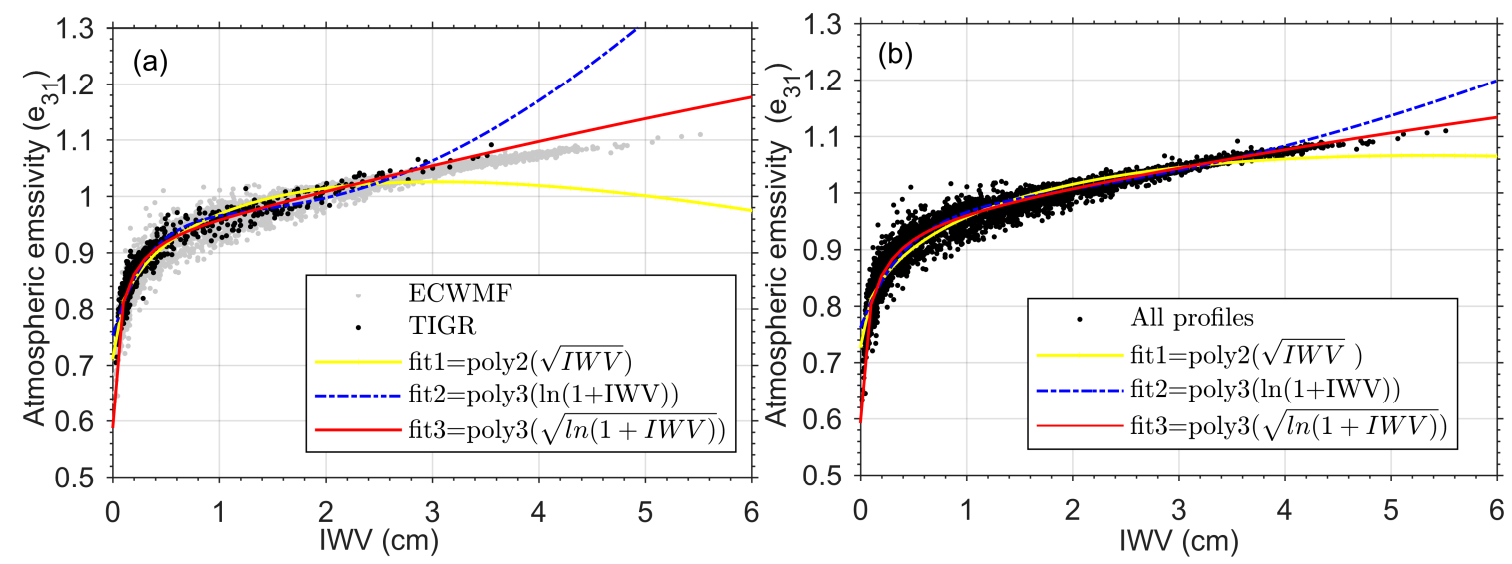

Figure 4. Atmospheric emissivity $\left(\varepsilon_{31}\right)$ defined by Equation (3) using brightness temperature (BT) of MODIS 31st channel, plotted as functions of IWV at the condition of conifer surface, $\mathrm{H}=1.435 \mathrm{~km}$, view zenith angle $(\mathrm{VZA})=0^{\circ}$, and $\delta T_{s, a}=0 \mathrm{~K}$. The black and gray dots represent TIGR2002 and ECWMF profiles, respectively. Only the TIGR2002 profiles were used in regression in Figure (a), and all the TIGR2002 and the ECWMF profiles were used in Figure (b). Poly2 and poly3 represent quadratic and cubic function, respectively.

The new formulation can greatly improve results compared with the Yu2013 algorithm at large IWV, especially when the profile number for regression is not large. Figure 5 shows the results of the two parameterizations when their coefficients were derived using only TIGR2002 profiles. The atmospheric emissivity was underestimated at large IWV for the Yu2013 parameterization, causing negative bias of DLR (Figure 5a,c). With the new parameterization, the negative bias of atmospheric emissivity was corrected, thereby improving the predicted DLRs (Figure $5 b, d$ ). As shown in the figure, the new parameterization reduced the root mean square error (RMSE) by 1.9 to $3.1 \mathrm{~W} / \mathrm{m}^{2}$ for $\delta T_{s, a}=0$ $K$. The DLR statistical error distribution for IWV greater than $3.0 \mathrm{~cm}$ is shown in Table 2. For small VZA $\left(<60^{\circ}\right)$, more than $99 \%$ of the DLRs had accuracy within $20 \mathrm{~W} / \mathrm{m}^{2}$, an improvement of $0.5 \%$ compared with Yu2013 algorithm. At large VZA $\left(=60^{\circ}\right)$, the accuracy increased by $16.9 \%$.

Subsequently, we derived a LUT of coefficients for the new parameterization at various elevation, VZA, and $\delta T_{s, a}$ values from the training dataset. We found the coefficients did not yield obvious differences between surface types except for dry grass, the same result as that in [36], because the emissivity spectrum of dry grass is obviously lower than other surface types in the thermal infrared range. Therefore, two sets of coefficients were derived, dry grass-only coefficients for arid surfaces and the all surfaces-average coefficients for other surfaces. Moreover, because $\delta T_{s, a}$ is difficult to retrieve accurately using MODIS data, we suggest that $\delta T_{s, a}$ is only used to surface with large $\delta T_{s, a}$, such as bare ground, arid region, snow, ice, etc. Also, we suggest setting $\delta T_{s, a}$ within $\pm 20 \mathrm{~K}$ in the DLR calculation to limit the error caused by inaccurate $\delta T_{s, a}$. 

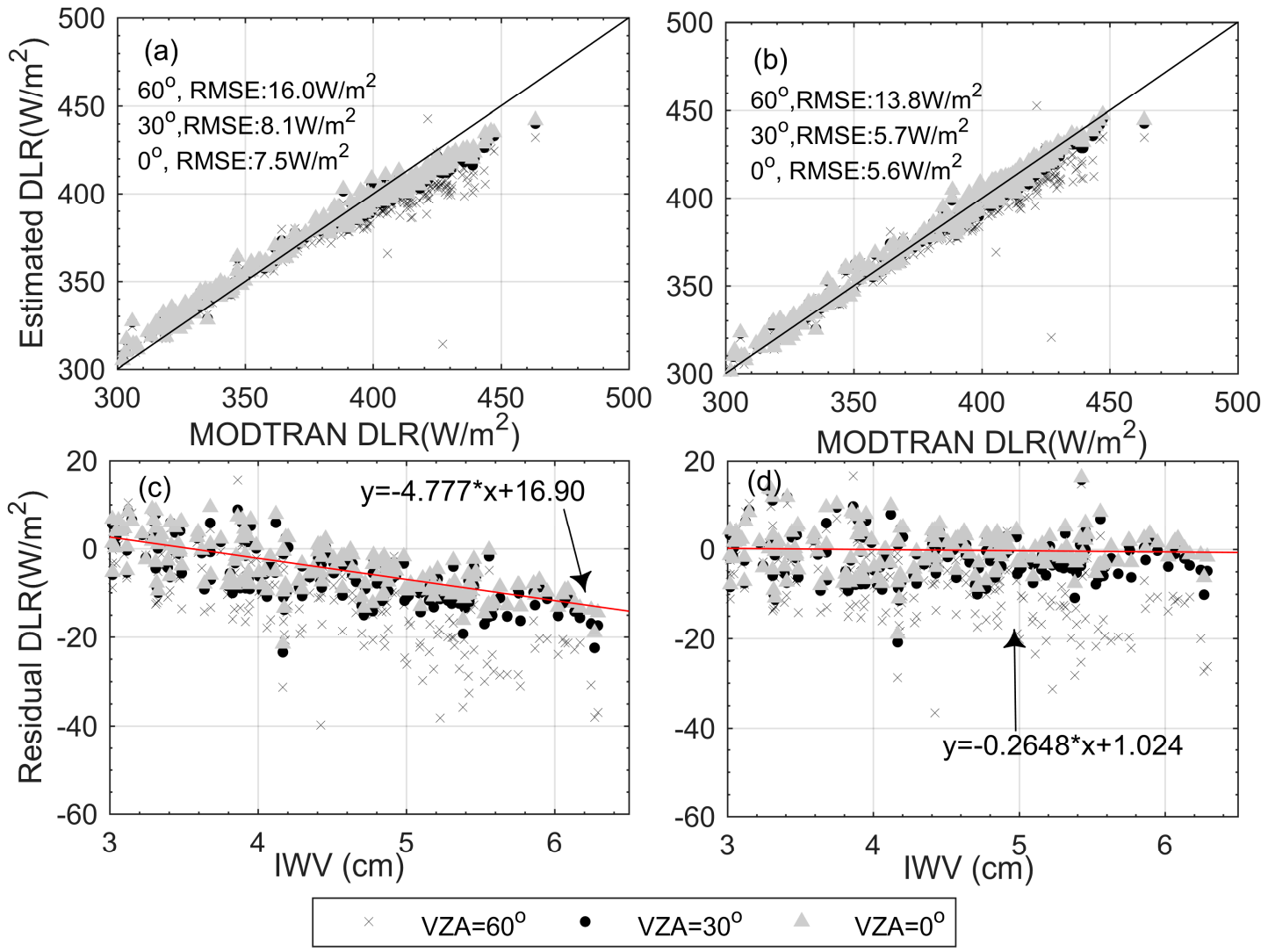

Figure 5. DLRs calculated from testing dataset using the Yu2013 (a,c) and new parameterizations (b,d), respectively. The algorithms coefficients were deriving from TIGR2002 profiles. Figures (a,b) show the comparison between the estimated and the MODTRAN-simulated DLRs. Figures (c,d) show the residuals of the predicted DLR, which vary with water vapor content for different VZAs, assuming $\delta T_{s, a}=0 \mathrm{~K}$.

Table 2. Error distribution statistics for IWV greater than $3.0 \mathrm{~cm}$ and $\delta T_{s, a}=0 \mathrm{~K}$.

\begin{tabular}{cccc}
\hline Sensor Zenith View Angle & Range of Error $\left(\mathbf{W} / \mathbf{m}^{2}\right)$ & Yu2013 & NewParam \\
\hline \multirow{2}{*}{$\mathrm{VZA}=0^{\circ}$} & {$[-20,15]$} & $99.5 \%$ & $100 \%$ \\
& {$[-40,-20]$} & $0.5 \%$ & $0 \%$ \\
\hline \multirow{2}{*}{$\mathrm{VZA}=30^{\circ}$} & {$[-20,15]$} & $98.9 \%$ & $99.5 \%$ \\
& {$[-40,-20]$} & $1.1 \%$ & $0.5 \%$ \\
\hline \multirow{2}{*}{$\mathrm{VZA}=60^{\circ}$} & {$[-20,15]$} & $73.8 \%$ & $90.7 \%$ \\
& {$[-40,-20]$} & $25.1 \%$ & $8.2 \%$ \\
\hline
\end{tabular}

\section{Algorithm Evaluation using Testing Dataset}

\subsection{Evaluation of Algorithm Accuracy}

DLRs were calculated from IWV and the simulated TOA BT of the testing dataset using the new parameterization and evaluated using MODTRAN-simulated DLRs. Table 3 indicates that most surfaces had similar retrieval accuracy (RMSE $=5.1-8.4 \mathrm{~W} / \mathrm{m}^{2}$ ), except of dry grass, which has a large negative error (bias $=-6.0 \mathrm{~W} / \mathrm{m}^{2}$ ). We further gave the DLR error statistics under different climatic conditions for the conifer surface. We found the RMSEs of daytime and nighttime, with and without temperature inversion, were $6.2,4.8,5.5$, and $5.6 \mathrm{~W} / \mathrm{m}^{2}$, respectively. Daytime DLRs had a larger positive error $\left(\sim 3.4 \mathrm{~W} / \mathrm{m}^{2}\right)$ than nighttime, and DLRs under temperature inversion conditions had a bias about $-3.1 \mathrm{~W} / \mathrm{m}^{2}$ greater than the conditions without temperature inversion. Based on detailed 
analysis, we found that the temperature inversion had a very small effect on DLR estimation for this algorithm, except that the near-surface temperature profile had a very thick layer with a strong lapse rate. Furthermore, some polar winter profiles had large negative errors. Figure 6a,d gives RMSE and bias variation with VZA for the conifer surface. RMSE increased with VZA from 5.6 to $20.2 \mathrm{~W} / \mathrm{m}^{2}$ for $\delta T_{s, a}=0 \mathrm{~K}$, and the bias was 1.8 to $-6.8 \mathrm{~W} / \mathrm{m}^{2}$. RMSE were 5.4 to $20.0 \mathrm{~W} / \mathrm{m}^{2}$ and 6.7 to $20.8 \mathrm{~W} / \mathrm{m}^{2}$ for $\delta T_{s, a}=-20$ and $20 \mathrm{~K}$, respectively.

Table 3. The mean value of actual and calculated DLRs (DLR $\mathrm{act}_{\text {and }}$ DLR $\mathrm{cal}$ ), root mean square error (RMSE), bias, maximum error and minimum error between actual DLRs, and those calculated from training datasets for different surface types when $\delta T_{s, a}=0 \mathrm{~K}$ and VZA $=0^{\circ}$ (unit: $\mathrm{W} / \mathrm{m}^{2}$ ).

\begin{tabular}{ccccccccc}
\hline Surface Types & Conifer & Soil & Wet Land & Concrete & Dry Grass & Sea Water & Fine Snow & All Types \\
\hline DLR $_{\text {act }}$ & 321.9 & 321.9 & 321.9 & 321.9 & 321.9 & 321.9 & 321.9 & 321.9 \\
DLR $_{\text {cal }}$ & 326.7 & 324.9 & 327.6 & 325.5 & 323.8 & 326.8 & 327.1 & 326.1 \\
RMSE & 5.6 & 5.4 & 6.7 & 5.1 & 8.4 & 5.7 & 6.0 & 6.2 \\
Bias & 1.8 & -1.9 & 3.8 & -0.6 & -6.0 & 2.2 & 2.8 & 0.3 \\
Max error & 16.8 & 11.7 & 19.6 & 13.5 & 10.4 & 17.3 & 18.2 & 19.6 \\
Min error & -24.0 & -25.3 & -23.3 & -24.9 & -26.3 & -23.9 & -23.7 & -26.3 \\
\hline
\end{tabular}

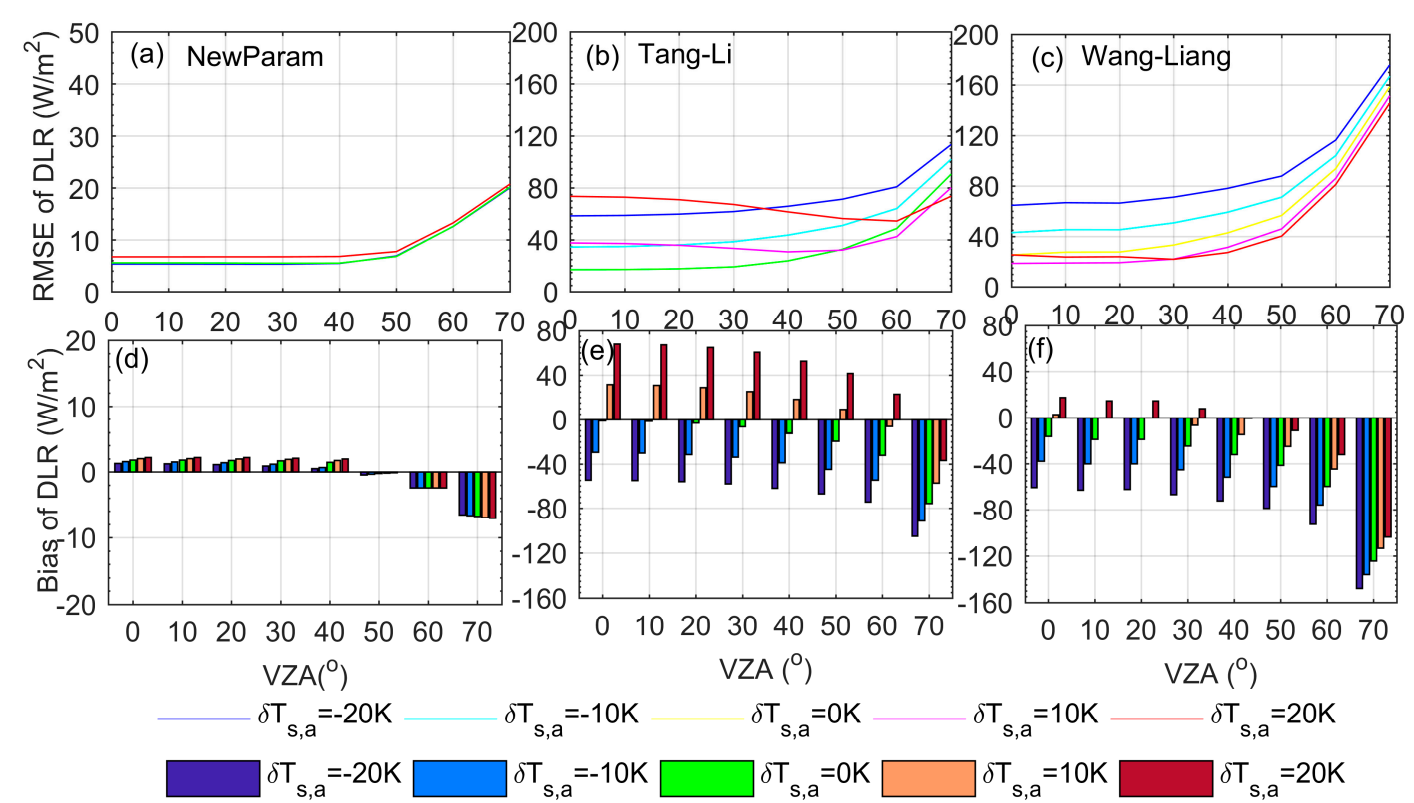

Figure 6. Figures (a-f) illustrate the RMSE and Mean-Bias-Error (MBE) between the actual and estimated DLRs versus VZA and $\delta T_{s, a}$ for conifer surface and for NewParam (a,d), Tang-Li algorithm $(\mathbf{b}, \mathbf{e})$, and Wang-Liang algorithm $(\mathbf{c}, \mathbf{f})$, respectively.

The new algorithm was compared with the four algorithms in Section 2.1. Though these algorithms were developed under different conditions, it was worth investigating their advantages and drawbacks by applying them to the testing data. The results of algorithms based on testing data are shown in Figures 6 and 7. As shown in Figure 6, the TOA radiance-based algorithms, Tang-Li and Wang-Liang, performed poorer than the new algorithm, and their DLR accuracies were largely dependent on $\delta T_{s, a}$ and VZA. The Tang-Li algorithm had the best result at $\delta T_{s, a}=0 \mathrm{~K}$ and performed worse when the absolute value of $\delta T_{s, a}$ became larger. This is because Ta was considered equal to Ts in the algorithm development [30]. For the Wang-Liang algorithm, RMSE and bias were minimal at $\delta T_{s, a}=10 \mathrm{~K}$ and increased at other $\delta T_{s, a}$ values. Though MODIS-derived Ta and Ts were used in the MODTRAN simulation during their algorithm development [31], the coefficients were not regressed for each $\delta T_{s, a}$ value separately. Therefore, they represented the average $\delta T_{s, a}$ of all training profiles. When VZA $\leq 40^{\circ}$, DLR RMSE is 17.0 to $23.8 \mathrm{~W} / \mathrm{m}^{2}$ for the Tang-Li algorithm at $\delta T_{s, a}=0 \mathrm{~K}$ and 18.7 to $31.4 \mathrm{~W} / \mathrm{m}^{2}$ for the Wang-Liang algorithm at $\delta T_{s, a}=10 \mathrm{~K}$. When VZA was larger, RMSEs of the two 
algorithms increased rapidly with VZA, especially for Wang-Liang algorithm, with RMSE reaching $151.5 \mathrm{~W} / \mathrm{m}^{2}$. Figure $7 \mathrm{a}, \mathrm{b}$ indicate that the large negative biases in DLR occurred at large VZA, which happened at high IWVs. Considering that the Wang-Liang algorithm was developed over the North American continent, 38 CLAR profiles in this region were analyzed. Results in the North American continent were similar to those worldwide except that the best result was at $\delta T_{s, a}=5 \mathrm{~K}$, and RMSE varied from 14.9 to $163.4 \mathrm{~W} / \mathrm{m}^{2}$ with VZA increase at $\delta T_{s, a}=10 \mathrm{~K}$.
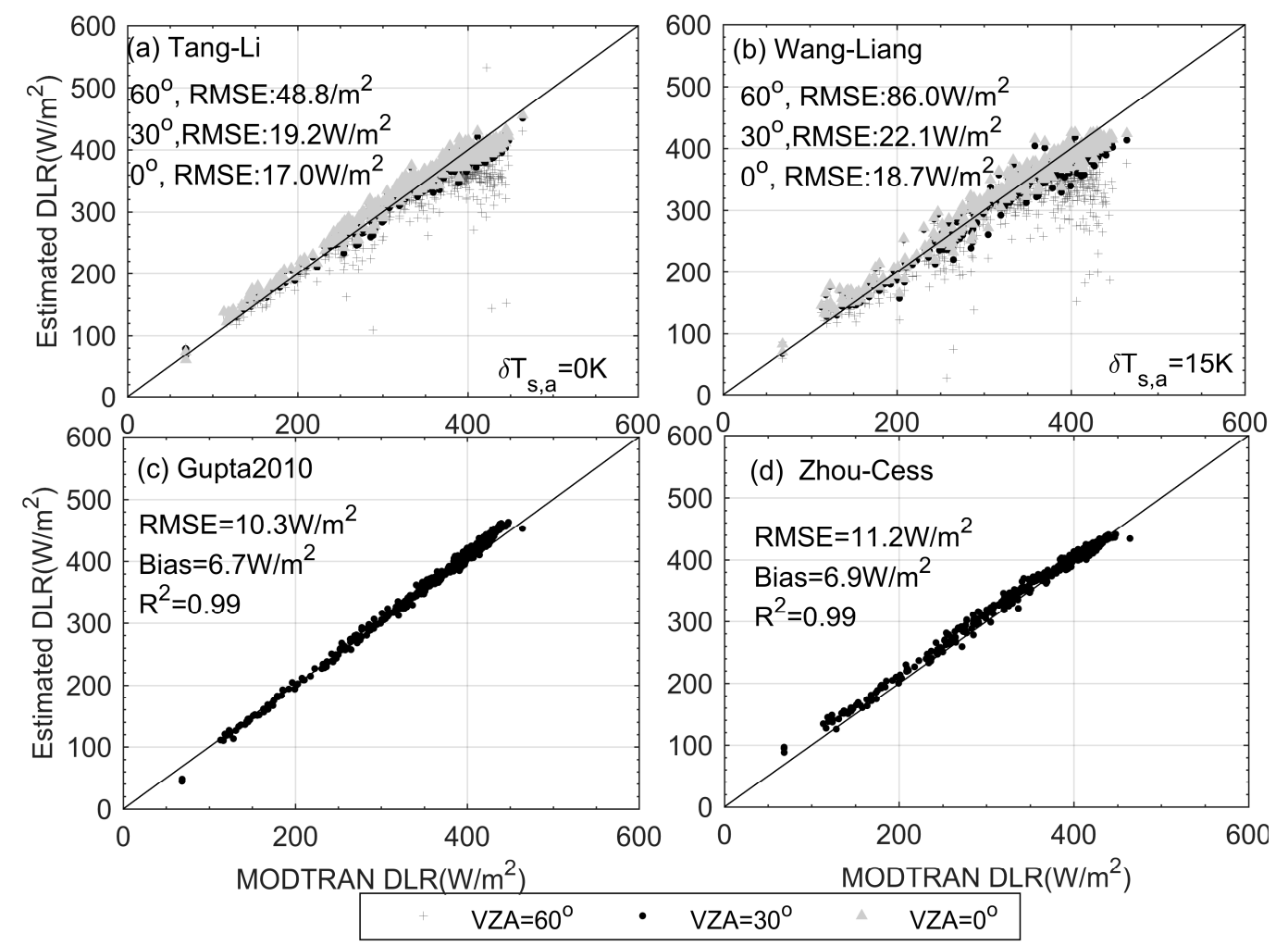

Figure 7. Comparison of the clear-sky flux calculated from DLR algorithms with those from MODTRAN simulation based on the testing dataset. Figures (a) to (d) represent Tang-Liang, Wang-Li, Gupta2010, and Zhou-Cess algorithms, respectively, and $\delta T_{s, a}$ is $0 \mathrm{~K}$ and $10 \mathrm{~K}$ in Figures (a,b).

The Gupta2010 and Zhou-Cess algorithms performed well, with RMSEs of 10.3 and $11.2 \mathrm{~W} / \mathrm{m}^{2}$ (Figure 7). The new parameterization had a smaller RMSE (about $5 \mathrm{~W} / \mathrm{m}^{2}$ ) than the two algorithms for VZA $\leq 50^{\circ}$ (comparing Figures 6 and 7) but had a slightly larger RMSE (about 1 to $9 \mathrm{~W} / \mathrm{m}^{2}$ ) than the other two algorithms at larger VZAs. However, when the two algorithms were applied to actual satellite data, DLRs from them were greatly influenced by the uncertainty of $T_{a}$, which was difficult to retrieve accurately using satellites, especially for those without the TIR sounding channels.

\subsection{Sensitivity Analysis of Input Parameters}

The sensitivity of three main inputs parameters, IWV, BT, and $\delta T_{\mathrm{s}, \mathrm{a}}$, were analyzed for three various climate types. As shown in Table 4, Cases 1, 2, and 3 were at the conditions of low-BT and low-IWV, high-BT and low-IWV, and high-BT and high-IWV, respectively. The three cases represent a dry and cold climate such as a polar region, a hot and dry climate such as a desert, and a wet and hot climate such as a tropical ocean, respectively. The sensitivity was defined as the DLR error versus the error of an input parameter while keeping the others fixed. The definition of each case and the error range of input parameters are given in Table 4 , and the results of sensitivity analysis are displayed in Figure 8. 
Table 4. The definition of each case and the error range of input parameters.

\begin{tabular}{clc}
\hline Input Parameter & Value of All Parameters & Error of Input Parameter \\
\hline \multirow{2}{*}{ IWV } & Case 1 $(\mathrm{BT}=260 \mathrm{~K}, \mathrm{IWV}=0.5 \mathrm{~cm}), \delta T_{s, a}=0 \mathrm{~K}$ & {$[-90 \%, 400 \%]$} \\
& Case 2 $(\mathrm{BT}=300 \mathrm{~K}, \mathrm{IWV}=0.5 \mathrm{~cm}), \delta T_{s, a}=0 \mathrm{~K}$ & {$[-90 \%, 400 \%]$} \\
& Case 3 $(\mathrm{BT}=300 \mathrm{~K}, \mathrm{IWV}=5.0 \mathrm{~cm}), \delta T_{s, a}=0 \mathrm{~K}$ & {$[-60 \%, 60 \%]$} \\
\hline BT & Case 1, Case 2, Case 3, $\delta T_{s, a}=0 \mathrm{~K}$ & {$[-20 \mathrm{~K}, 20 \mathrm{~K}]$} \\
\hline \multirow{2}{*}{$\delta T_{s, a}$} & Case 1, Case 2, Case 3, $\delta T_{s, a}=-10 \mathrm{~K}$ & {$[-5 \mathrm{~K}, 5 \mathrm{~K}]$} \\
& Case 1, Case 2, Case 3, $\delta T_{s, a}=10 \mathrm{~K}$ & {$[-20 \mathrm{~K}, 20 \mathrm{~K}]$} \\
\hline
\end{tabular}
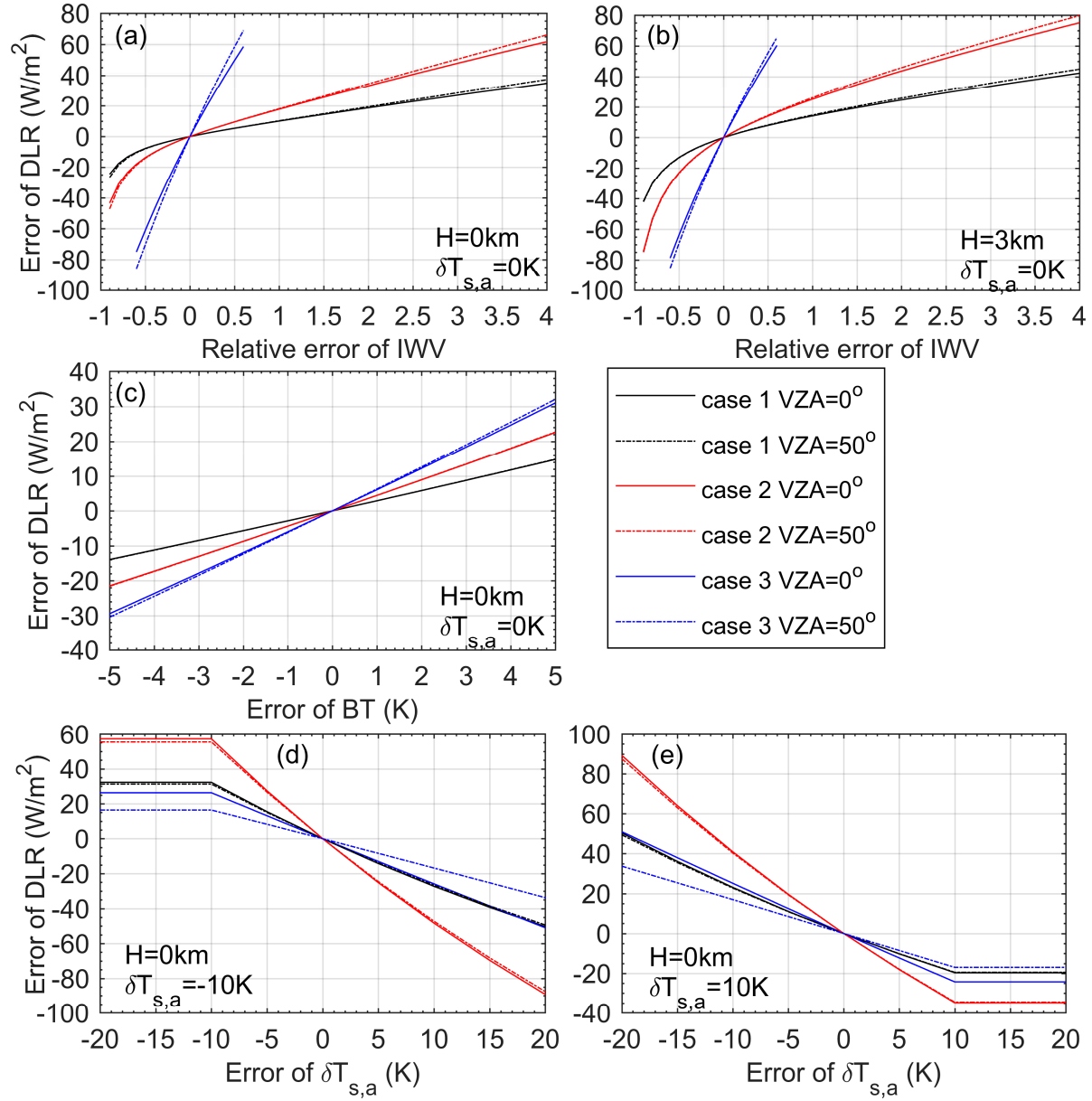

Figure 8. DLR error versus the error of input parameters such as IWV $(\mathbf{a}, \mathbf{b})$, brightness temperature (c), and $\delta T_{\mathrm{s}, \mathrm{a}}(\mathbf{d}, \mathbf{e})$ under different climate conditions. Cases 1, 2, and 3 represent the conditions of $\mathrm{BT}=260 \mathrm{~K}$ and IWV $=0.5 \mathrm{~cm}, \mathrm{BT}=300 \mathrm{~K}$ and $\mathrm{IWV}=0.5 \mathrm{~cm}$, and BT $=300 \mathrm{~K}$ and $\mathrm{IWV}=5.0 \mathrm{~cm}$, respectively. Figures $(\mathbf{a}, \mathbf{b})$ are for $\mathrm{H}=0$ and $3.0 \mathrm{~km}$, respectively. Figures $(\mathbf{d}, \mathbf{e})$ represent the conditions of $\delta T_{\mathrm{s}, \mathrm{a}}=-10$ and $10 \mathrm{~K}$, respectively.

\subsubsection{Sensitivity to Water Vapor Content Error}

Figure $8 \mathrm{a}, \mathrm{b}$ shows the DLR error to IWV relative error (RE) at elevation of 0 and $3 \mathrm{~km}$, respectively. We found that satellite retrieved IWVs were sometimes 10 times smaller or larger than the actual data at very small IWVs, and IWV RE was relatively small at large IWVs. Therefore, we set different IWV RE for different conditions; they were set within $\pm 60 \%$ for high IWV conditions (Case 3 ) and within $-90 \%$ to $400 \%$ for low IWVs (Cases 1 and 2). DLR error was small for IWV RE within $\pm 50 \%$ under low-IWV conditions, i.e., -7.8 to $5.4 \mathrm{~W} / \mathrm{m}^{2}$ and -13.7 to $9.5 \mathrm{~W} / \mathrm{m}^{2}$ for Cases 1 and 2 when elevation $=0 \mathrm{~km}$ and VZA $=0^{\circ}$. However, when the IWV RE range was -90 to $400 \%$, DLR had a larger error, -24.5 to $34.8 \mathrm{~W} / \mathrm{m}^{2}$ and -43.5 to $61.7 \mathrm{~W} / \mathrm{m}^{2}$ for Cases 1 and 2 . DLR was most sensitive to IWV 
uncertainty under high-IWV conditions (Case 3), with a DLR error of -74.9 to $58.6 \mathrm{~W} / \mathrm{m}^{2}$ for IWV RE within 60\%. Moreover, DLR was slightly more sensitive to IWV at larger VZAs, but the DLR error difference between $\mathrm{VZA}=0^{\circ}$ and $50^{\circ}$ could be considered negligible (about 0 to $2 \mathrm{~W} / \mathrm{m}^{2}$ ) unless the IWV or the IWV error was very large. Compared with low elevation, IWV uncertainty produced much larger DLR errors when IWV RE was large for low-IWV conditions at high elevation (Figure 8b). DLR error was -41.9 to $42.3 \mathrm{~W} / \mathrm{m}^{2}$ and -74.3 to $75.1 \mathrm{~W} / \mathrm{m}^{2}$ for Cases 1 and 2 , with a DLR RE of -23.8 to $24.1 \%$ for both conditions. Nevertheless, DLR errors for high IWV were very similar to those at low altitude.

\subsubsection{Sensitivity to Brightness Temperature Error}

The BT error was from an instrument calibration error and spatial mismatch between the ground station and the satellite pixel. Compared to the former error, the latter error was very large in rugged areas and under cloud contamination conditions. As shown in Figure $8 \mathrm{c}$, the DLR error showed a linear relationship with the BT error when it was -5 to $5 \mathrm{~K}$. For altitude $=0 \mathrm{~km}$ and VZA $=0^{\circ}$, the DLR error of Case 1 was -13.9 to $14.8 \mathrm{~W} / \mathrm{m}^{2}$ and RE was -7.5 to $7.9 \%$ (not shown). The DLR error was more sensitive to BT at high-BT conditions at -21.5 to $22.5 \mathrm{~W} / \mathrm{m}^{2}$ for Case 2 and -29.5 to $31.0 \mathrm{~W} / \mathrm{m}^{2}$ for Case 3 .

\subsubsection{Sensitivity to Error in Temperature Difference between Ground and Air}

Figure $8 \mathrm{~d}$,e show the DLR sensitivity to the error of $\delta T_{s, a}$ when the ground was $10 \mathrm{~K}$ cooler or warmer than the surface air. The DLR error linearly increased with the absolute error $\delta T_{s, a}$ and reached its positive (or negative) maximum when the $\delta T_{s, a}$ error was $-10 \mathrm{~K}$ (or $10 \mathrm{~K}$ ) for $\delta T_{s, a}=-10 \mathrm{~K}$ (or $10 \mathrm{~K}$ ) because $\delta T_{s, a}$ was set within $\pm 20 \mathrm{~K}$ in the DLR calculation. DLR was more sensitive to $\delta T_{s, a}$ for high-BT and low-IWV conditions (Case 2) than other cases. Furthermore, the DLR error difference between $0^{\circ}$ and $50^{\circ}$ was only 1 to $2 \mathrm{~W} / \mathrm{m}^{2}$ for Cases 1 and 2 , but it reached $17.3 \mathrm{~W} / \mathrm{m}^{2}$ for Case 3 . The figure indicated that if $\delta T_{s, a}$ was ignored in DLR estimation, which meant the $\delta T_{s, a}$ error was $10 \mathrm{~K}$ (or $-10 \mathrm{~K}$ ) for $\delta T_{s, a}=-10 \mathrm{~K}$ (or $10 \mathrm{~K}$ ), DLR would be underestimated by $27.3,48.3$, and $25.9 \mathrm{~W} / \mathrm{m}^{2}$ (or overestimated by $23.1,40.9$, and $25.2 \mathrm{~W} / \mathrm{m}^{2}$ ) for Cases 1,2 , and 3 for VZA $=0^{\circ}$. Therefore, we suggest that $\delta T_{s, a}$ should be considered for the bare soil, sand, and dry grass surfaces, especially for deserts where higher $T_{s}$ and lower $T_{a}$ and high BT and low IWV frequently exist in the daytime. Also, the $\delta T_{s, a}$ is non-negligible for an ice surface where $T_{s}$ is much lower than $T_{a}$.

The above sensitivity analysis indicates that DLR accuracy in actual application is greatly affected by uncertainties of IWV, BT, and $\delta T_{s, a}$. When RE of IWV is within $50 \%$, it produces a very large error into DLR retrieval for large IWVs (i.e., $5 \mathrm{~cm}$ ), and a relatively smaller DLR error for small IWVs (i.e., $0.5 \mathrm{~cm}$ ). However, IWV RE is usually much larger than $50 \%$ under small IWV conditions and therefore leads to a large error of DLR. Moreover, an IWV error leads to larger error of DLR at high elevations than that at low elevations. The BT error caused by the spatial mismatch of pixel and field in rugged areas and by the cloud contamination causes a significant error to DLR retrievals; $10 \mathrm{~K}$ error in $\delta T_{s, a}$ causes an error of about 20 to $40 \mathrm{~W} / \mathrm{m}^{2}$ to DLR. Therefore, $\delta T_{s, a}$ should be considered under the conditions that $T_{s}$ is very different from $T_{a}\left(\delta T_{s, a}=-10 \mathrm{~K}\right.$ or $\left.10 \mathrm{~K}\right)$, which is related to bare soil, sand, dry grass, and ice surfaces. For the input parameters of IWV and BT, DLR is more sensitive to their errors under high BT and high IWV conditions than under other conditions, whereas for $\delta T_{s, a}, \mathrm{DLR}$ is most sensitive to errors under high BT and low IWV conditions. 


\section{Validation Results of Satellite Retrieved DLRs}

\subsection{Satellite and Surface Data}

\subsubsection{MODIS data}

The collection 6.0 MODIS products were used, including MOD021KM, MOD03, MOD35_L2 [43], MOD05_L2 [44,45], and MOD07_L2 [46]. The input parameters of the new parameterization and the four algorithms for comparison are shown in Table 5. We used near-infrared water vapor from MOD05_L2 in the daytime and the infrared IWV in the nighttime when the near-infrared water vapor data were unavailable. MOD07_L2 furnishes $T_{S}$, surface pressure, and temperature and moisture profiles at 20 pressure levels. Surface $T_{a}$ was acquired by interpolating MODIS temperature at the lowest pressure level to the surface altitude, assuming a temperature lapse rate of $6.5 \mathrm{~K} / \mathrm{km}$ [18]. Then, $\delta T_{s, a}$ and the mean temperatures of the lowest two layers for the Gupta2010 algorithm were calculated. The lowest two atmospheric layers were defined as the surface to $780 \mathrm{hPa}$ and 780 to $700 \mathrm{hPa}$ when surface pressure was $\sim 1000 \mathrm{hPa}$, whereas both layers were $\sim 100 \mathrm{hPa}$ thick over high-altitude regions. The lowest layer was defined as at least $25 \mathrm{hPa}$ above the surface to guarantee that the temperature lapse rate was applied to a layer at least $25 \mathrm{hPa}$ in thickness [47].

Table 5. Input parameters and data sources used in this study.

\begin{tabular}{ccc}
\hline Parameters & Data Source & Algorithms Requiring the Data \\
\hline Geolocation information and & MOD03, at $1 \mathrm{~km}$ & All algorithms \\
elevation & MOD35, at $1 \mathrm{~km}$ & All algorithms \\
Cloud mask & MOD03, at $1 \mathrm{~km}$ & NewParam, Tang-Li, Wang-Liang \\
Viewing zenith angle & MOD021KM, at $1 \mathrm{~km}$ & NewParam, Tang-Li, Wang-Liang \\
TIR channel radiance & MOD05, at $1 \mathrm{~km}$ for daytime and 5 & NewParam, Zhou-Cess, \\
Water vapor content & km for nighttime & Gupta2010 \\
& MOD07, at $5 \mathrm{~km}$ & Gupta2010 \\
Atmospheric profiles & MOD07, at $5 \mathrm{~km}$ & NewParam, Zhou-Cess, \\
Air and surface temperatures & & Gupta2010 \\
& & \\
\hline
\end{tabular}

\subsubsection{NCEP Data and Atmospheric Parameter Derivation}

Li et al. [48] found that the MODIS's profile lacked lower-atmospheric data for high-altitude regions. To evaluate the performance of different atmospheric products in DLR calculation, National Centers for Environmental Prediction (NCEP) data with higher vertical resolution were used and compared with MODIS. The NCEP FNL (Final) Operational Global Analysis data were prepared operationally every six hours at $1^{\circ} \times 1^{\circ}$ resolution. The NCEP data provided several parameters required by the study, including surface pressure, total water vapor content, 2-m air temperature, surface temperature, and atmospheric profiles. The atmospheric profiles included temperature and relative humidity at 26 levels from 1000 to $10 \mathrm{hPa}(1000,975,950,925,900,850,800,750,700,650,600$, $550,500,450,400,350,300,250,200,150,100,70,50,30,20$, and $10 \mathrm{hPa}$ ).

The atmospheric parameters for DLR retrieval, including $T_{a}, \mathrm{IWV}, T_{s}, T_{e}$, and atmospheric profiles, were obtained from NCEP, and the other inputs were unchanged. The profiles were obtained by interpolation from the $1^{\circ} \times 1^{\circ}$ original grid into a $1 \mathrm{~km} \times 1 \mathrm{~km}$ mesh. We used the method proposed by [47] to extract the satellite pixel profile and other parameters from the NCEP data, including temporal, spatial, and vertical interpolation. First, two NCEP files representing two adjacent forecast times were loaded and interpolated to the satellite time using linear interpolation with time difference. Then, the profiles at satellite pixel were extracted by bilinear interpolation from the four grid corners surrounding a specific location. Finally, the $T_{a}$ and humidity at the surface level were bilinearly interpolated from the two closest layers to the surface. $T_{S}$ was obtained after temporal and spatial interpolation, whereas $T_{a}, T_{e}$, and IWV were calculated from the final atmospheric profile. 


\subsubsection{Ground Measurements}

DLR measurements were collected from 14 sites around the globe belonging to either the Chinese Watershed Allied Telemetry Experimental Research (WATER; [49]), the Atmospheric Radiation Measurement (ARM) Program, the international Baseline Surface Radiation Network (BSRN), or the Ameriflux. The information about site location, period, instrument, and measurement uncertainty are presented in Table 6 . The sites are in various climate types including polar regions with dry and cold climate, tropical marine climate with high temperature and IWV, and arid regions with low IWV and large $\delta T_{s, a}$. The arid sites are marked with asterisks, including the desert surface and the sites that were considered as arid by [22]. All sites are a homogeneous surface type, and most of them are in flat and rural regions. The homogeneity of the sites was analyzed using ASTER global digital elevation model (DEM) data with $30-\mathrm{m}$ resolution. The standard deviation of elevation within a $3 \mathrm{~km} \times 3 \mathrm{~km}$ is 4-40 $\mathrm{m}$ for most sites; it is about $347 \mathrm{~m}$ for Dome C (DOM), which is relatively small compared with the site altitude and has little influence on DLR calculation. Therefore, all sites can be regarded as homogeneous in the validation.

The radiation data provided by WATER, ARM, BSRN, and Ameriflux sites were in 10-min, 1-min, 1-min and 30-min average, respectively. For the sites from the former three networks, the data closest to the satellite overpass time were chosen, while for the Ameriflux sites, in-situ DLR was interpolated from the two data points that were closest to the satellite pass time. Besides surface radiations, the three sites of ARM and South Pole (SPO) of BSRN provided discontinuous measurements of IWV. One year of data were used for most sites, whereas field measurements were discontinuous during 2010 at DOM, and only summer and winter data were used for NSA-C1 and SPO because the Terra-MODIS passes overhead as many as eight times per day at these sites.

DLR was measured by Eppley Precision Infrared Radiometer (PIRs), CG3 pyrgeometers of Kipp \& Zonen CNR1 Net Radiometers, or Kipp \& Zonen CG 4 pyrgeometers at these sites. For the ARM network, the Eppley PIRs were shaded and ventilated to prevent excessive heating of the dome by the sun and were equipped with the Solar Infrared Radiation Station (SIRS) system at SGP-C1 and with the Sky Radiation (SKYRAD) system at Barrow North Slope of Alaska (NSA-C1) and Manus Island Tropical Western Pacific (TWP-C1). Their DLR measurement uncertainties were provided by Stoffel [50,51]. PIR accuracy for the BSRN DLR reached $10 \mathrm{~W} / \mathrm{m}^{2}$ through improvement of its calibration [52]. DLR uncertainties used the factory accuracies for other sites. The spectral ranges of the CG3, PIR, and CG4 were 5-50, 4.0-50, and 4.5-42 $\mu \mathrm{m}$, respectively. Although the spectral response functions of the pyrgeometers did not cover the whole infrared spectrum, their readings were calibrated to the total range of longwave emission [53]. 
Table 6. Description of site conditions. Sites used as examples of dry-arid regions are marked with asterisks.

\begin{tabular}{|c|c|c|c|c|c|c|c|c|}
\hline Site Label & Geographic Name & Latitude/Longitude $\left({ }^{\circ}\right)$ & Elevation $(m)$ & Period & Surface Type & Instrument & DLR Accuracy & Network \\
\hline YK & Yingke oasis station, China & $38.850 / 100.417$ & 1519 & 2010 & Cropland & Kipp \& Zonen CNR1 & $\pm 10 \%$ & WATER \\
\hline AR & Arou freeze/thaw station, China & $38.050 / 100.450$ & 3033 & 2010 & Grass & Eppley PIR & $\pm 5 \%$ & WATER \\
\hline $\mathrm{HZZ} *$ & Huazhaizi desert station, China & $38.767 / 100.317$ & 1726 & 2010 & Desert & Kipp \& Zonen CNR1 & $\pm 10 \%$ & WATER \\
\hline SGP-C1 & $\begin{array}{c}\text { South Great Plains, Central Facility, } \\
\text { America }\end{array}$ & $36.600 /-97.500$ & 318 & 2010 & Grass & Eppley PIR & $\begin{array}{l} \pm 2.5 \% \text { or } \pm 4 \\
\mathrm{~W} / \mathrm{m}^{2}\end{array}$ & ARM \\
\hline NSA-C1 & $\begin{array}{c}\text { Barrow, North Slope of Alaska, } \\
\text { America }\end{array}$ & $71.300 /-156.600$ & 7.6 & 2010 & Tundra & Eppley PIR & $\pm 6 \mathrm{~W} / \mathrm{m}^{2}$ & ARM \\
\hline TWP-C1 & $\begin{array}{c}\text { Manus Island, Tropical Western } \\
\text { Pacific }\end{array}$ & $-2.100 / 147.400$ & 4 & 2010 & Grass & Eppley PIR & $\pm 6 \mathrm{~W} / \mathrm{m}^{2}$ & ARM \\
\hline $\mathrm{ASP} *$ & Alice Springs, Australia & $-23.798 / 133.888$ & 547 & 2010 & Grass & Eppley PIR & $\pm 10 \mathrm{~W} / \mathrm{m}^{2}$ & BSRN \\
\hline DOM & Dome C, Antarctica & $-75.100 / 123.383$ & 3233 & $2010,[1,2]$ & Glacier & Kipp \& Zonen CG4 & $\pm 3 \%$ & BSRN \\
\hline DRA * & Desert Rock, America & $36.626 /-116.018$ & 1007 & 2010 & Desert & Eppley PIR & $\pm 10 \mathrm{~W} / \mathrm{m}^{2}$ & BSRN \\
\hline $\mathrm{SBO} *$ & Sede Boqer, Israel & $30.905 / 34.782$ & 500 & 2010 & Desert & Eppley PIR & $\pm 10 \mathrm{~W} / \mathrm{m}^{2}$ & BSRN \\
\hline $\mathrm{SPO}$ & South Pole, Antarctica & $-89.983 /-24.799$ & 2800 & $2010,[1,7,8]$ & Glacier & Eppley PIR & $\pm 10 \mathrm{~W} / \mathrm{m}^{2}$ & BSRN \\
\hline TAM * & Tamanrasset, Algeria & $22.780 / 5.510$ & 1385 & 2010 & Desert & Eppley PIR & $\pm 10 \mathrm{~W} / \mathrm{m}^{2}$ & BSRN \\
\hline FMF & Flagstaff Managed Forest, Arizona & $35.1426 /-111.7273$ & 2160 & 2010 & Forest & Kipp \& Zonen CNR1 & $\pm 10 \%$ & Ameriflux \\
\hline GLEES & US-GLE Wyoming, USA & $41.3644 /-106.2394$ & 3190 & 2010 & Forest & Eppley PIR & $\pm 5 \%$ & Ameriflux \\
\hline
\end{tabular}




\subsection{Validation Result of MODIS-Derived DLRS}

The pixels that the MODIS cloud mask considered to be clear at $95 \%$ and $99 \%$ probability were selected, and those lacking information about atmospheric profile or water vapor were removed as cloudy. Because the MODIS cloud mask may have substantial uncertainty in polar regions, we determined clear-sky conditions from field measurements at DOM, SPO, and NSA-C1 using the dual-threshold method proposed by [54]. The clear-sky threshold and standard deviation threshold of DLR for each month were selected according to the time series of DLR measurements and the clear-sky DLRs simulated by MODTRAN and in-situ atmospheric profiles. The measurements for DLR that were greater than a monthly clear-sky DLR threshold or DLR standard deviation over a 20-min period greater than the monthly standard deviation threshold were removed as cloudy conditions. Furthermore, the pixels with unreasonably low TOA radiance at sites Flagstaff Managed Forest (FMF) and US-GLE Wyoming (GLEES) and those with very low IWV at TWP-C1 were excluded as cloud contaminated.

The DLRs of MODIS clear-sky pixels were calculated and compared with in-situ measurements. As shown in Table 7, the validation results were arranged into three region types-the sites belonging to the arid region, the sites belonging to the high-altitude region (elevation $>2000 \mathrm{~m}$ ), and other sites belonging to ordinary regions. The statistical results for each site and their averages for each region type are presented. The scatter plots of estimated and ground-measured DLRs for the three region types are shown in Figures 9-11.

(a) NewParam

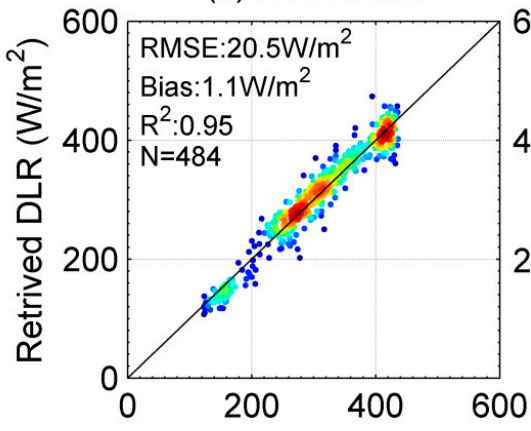

(d) Tang-Li

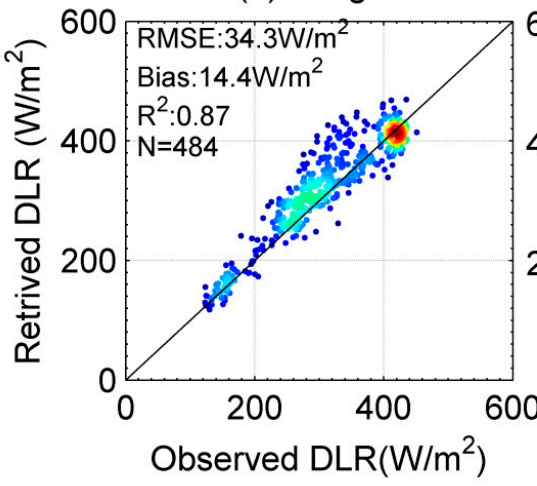

(b) Zhou-Cess

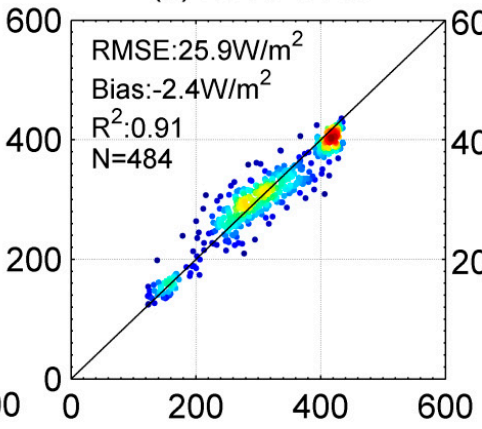

(e) Wang-Liang

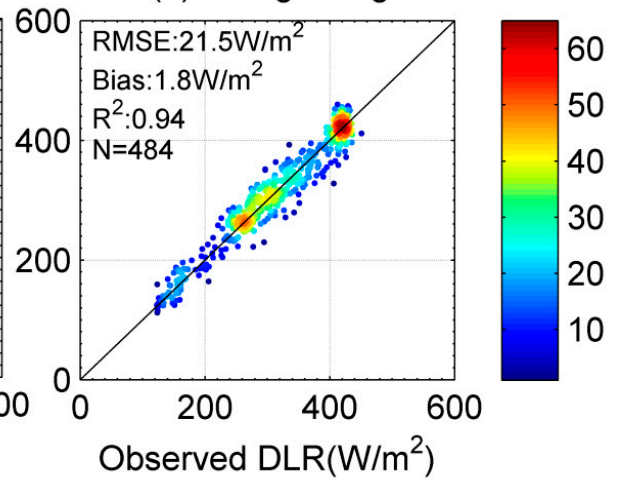

Figure 9. Comparison between MODIS-estimated DLRs and in-situ measurements at the sites in ordinary regions. Figures (a) to (e) represent the results from the new parameterization (NewParam), Tang-Li, Wang-Liang, Zhou-Cess, and Gupta2010 algorithms. The color bar represents data density that ranges from 0 to 100 percent of the data. 
Table 7. Error statistics for MODIS-derived clear-sky DLR using different algorithms. RMSE, bias, and the square of the correlation coefficients ( $\mathrm{R}^{2}$ ) of all sites and the average values of each type of region are given. RMSE and bias are in units of $\mathrm{W} / \mathrm{m}^{2}$. The best results are highlighted in bold, and the worst results are marked with asterisks.

\begin{tabular}{|c|c|c|c|c|c|c|c|c|c|c|c|c|c|c|c|}
\hline \multirow{2}{*}{ Site Label } & \multicolumn{3}{|c|}{ NewParam } & \multicolumn{3}{|c|}{ Tang-Li } & \multicolumn{3}{|c|}{ Wang-Liang } & \multicolumn{3}{|c|}{ Zhou-Cess } & \multicolumn{3}{|c|}{ Gupta2010 } \\
\hline & RMSE & Bias & $\mathbf{R}^{2}$ & RMSE & Bias & $\mathbf{R}^{2}$ & RMSE & Bias & $\mathbf{R}^{2}$ & RMSE & Bias & $\mathbf{R}^{2}$ & RMSE & Bias & $\mathbf{R}^{2}$ \\
\hline \multicolumn{16}{|c|}{ Sites in ordinary regions $(\mathrm{DEM}<2000 \mathrm{~m})$} \\
\hline YK & 23.5 & 1.2 & 0.85 & 23.3 & -1.9 & 0.83 & 24.1 & -12.2 & 0.86 & $35.4 *$ & -21.6 & 0.74 & 21.3 & -9.3 & 0.88 \\
\hline SGP-C1 & 19.4 & 8.0 & 0.91 & $50.2 *$ & 39.8 & 0.75 & 21.6 & 2.4 & 0.86 & 24.1 & 7.8 & 0.85 & 25.6 & 16.9 & 0.91 \\
\hline NSA-C1 & 17.7 & -1.8 & 0.95 & $24.6 *$ & 13.3 & 0.93 & 20.3 & 10.1 & 0.94 & 20.6 & 10.4 & 0.94 & 17.7 & -6.3 & 0.95 \\
\hline TWP-C1 & $22.3^{*}$ & -9.2 & 0.05 & 19.2 & -8.1 & 0.01 & 19.9 & 6.8 & 0.00 & 20.5 & -16.1 & 0.18 & 19.3 & -11.3 & 0.15 \\
\hline Mean & 20.5 & 1.1 & 0.95 & $34.3 *$ & 14.4 & 0.87 & 21.5 & 1.8 & 0.94 & 25.9 & -2.4 & 0.91 & 21.7 & 0.1 & 0.94 \\
\hline \multicolumn{16}{|c|}{ Sites in dry-arid regions } \\
\hline $\mathrm{HZZ}$ & 24.3 & -6.5 & 0.90 & 26.7 & 11.8 & 0.84 & 33.2 & -9.0 & 0.82 & 33.2 & -25.1 & 0.84 & 26.3 & -20.5 & 0.91 \\
\hline ASP & 19.5 & 0.6 & 0.82 & $49.9^{*}$ & 40.7 & 0.66 & 24.0 & 12.6 & 0.77 & 18.0 & -6.9 & 0.85 & 18.4 & -9.6 & 0.86 \\
\hline DRA & 26.8 & 7.4 & 0.79 & $48.6^{*}$ & 35.7 & 0.67 & 30.2 & -21.5 & 0.79 & 23.7 & -2.9 & 0.73 & 21.7 & -1.9 & 0.81 \\
\hline SBO & 23.9 & 0.8 & 0.72 & $48.6^{*}$ & 36.4 & 0.59 & 27.7 & -3.3 & 0.63 & 26.1 & -13.4 & 0.66 & 26.1 & -13.8 & 0.71 \\
\hline TAM & 21.9 & 6.7 & 0.77 & 34.4 & 16.9 & 0.46 & $39.2 *$ & -17.5 & 0.27 & 18.1 & -3.6 & 0.81 & 18.4 & 3.4 & 0.84 \\
\hline Mean & 23.3 & 3.3 & 0.80 & $43.6^{*}$ & 29.3 & 0.61 & 31.9 & -9.0 & 0.60 & 22.8 & -8.0 & 0.77 & 22.3 & -1.6 & 0.81 \\
\hline \multicolumn{16}{|c|}{ Sites in high-altitude regions (DEM $\geq 2000 \mathrm{~m}$ ) } \\
\hline $\mathrm{AR}$ & 23.7 & 9.6 & 0.82 & 23.7 & 8.6 & 0.71 & 21.4 & -4.3 & 0.74 & 27.1 & -10.4 & 0.67 & $27.2 *$ & -18.8 & 0.83 \\
\hline DOM & 7.8 & 1.4 & 0.56 & 23.3 & 18.0 & 0.31 & 13.4 & 2.9 & 0.30 & $34.8 *$ & 34.0 & 0.57 & 12.4 & 9.8 & 0.58 \\
\hline $\mathrm{SPO}$ & 15.5 & -10.6 & 0.83 & 17.3 & 0.5 & 0.77 & 25.3 & -17.3 & 0.94 & 29.6 * & 27.0 & 0.78 & 24.3 & -12.6 & 0.71 \\
\hline FMF & 22.5 & -8.2 & 0.80 & 26.3 & -0.1 & 0.66 & 19.4 & 5.3 & 0.83 & 23.8 & 3.0 & 0.74 & 17.9 & 5.3 & 0.87 \\
\hline GLEES & 35.7 & 6.3 & 0.62 & 33.3 & 12.6 & 0.65 & 29.4 & 10.9 & 0.72 & 45.4 & 14.2 & 0.39 & 34.6 & 8.7 & 0.61 \\
\hline Mean & 22.1 & -0.6 & 0.94 & 25.8 & 9.5 & 0.92 & 23.1 & 6.1 & 0.94 & $33.5^{*}$ & 15.3 & 0.89 & 23.1 & 0.1 & 0.93 \\
\hline
\end{tabular}


(a) NewParam

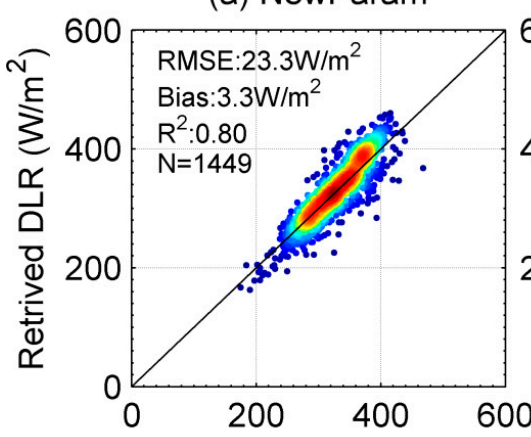

(d) Tang-Li

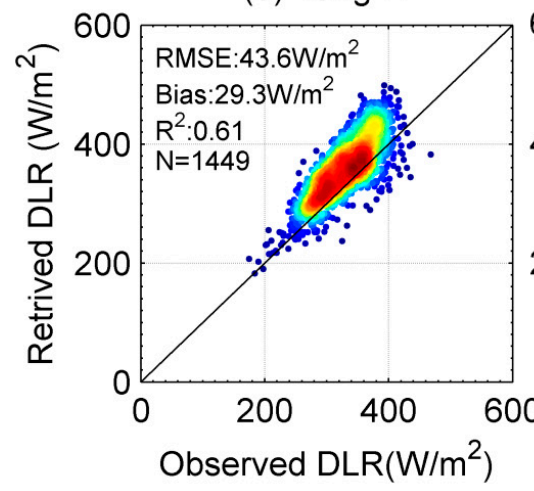

(b) Zhou-Cess

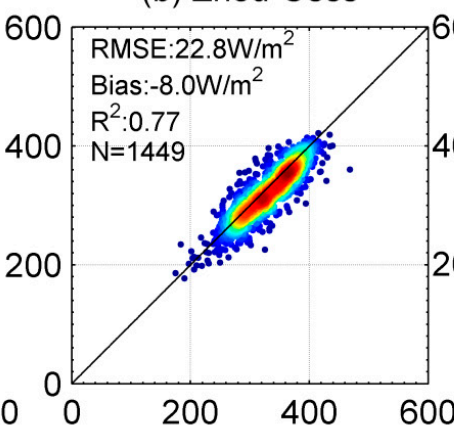

(e) Wang-Liang

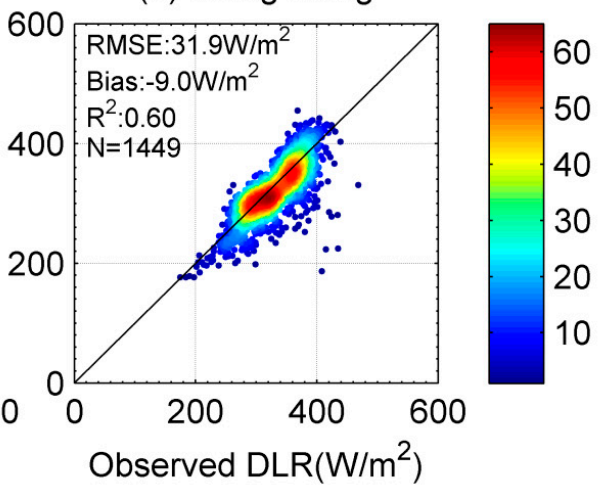

(c) Gupta2010

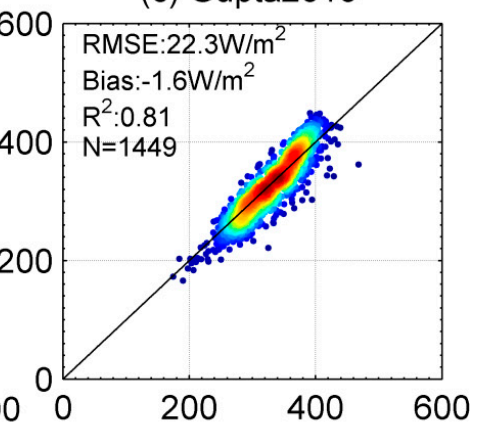

Figure 10. Same as Figure 9 but for the sites in the arid regions. Figures (a) to (e) represent the results from NewParam, Tang-Li, Wang-Liang, Zhou-Cess, and Gupta2010 algorithms.

(a) NewParam

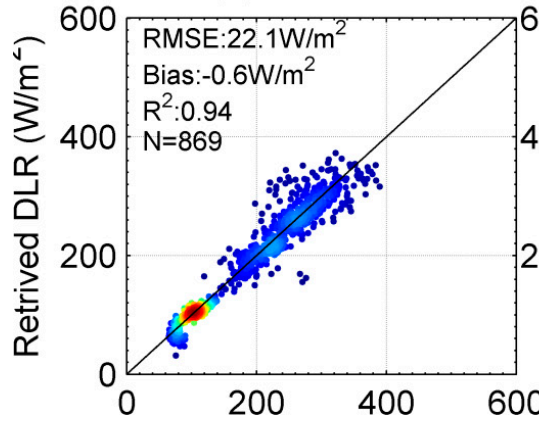

(d) Tang-Li

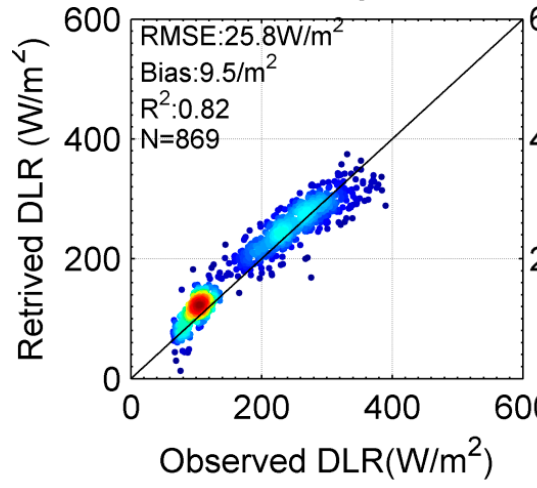

(b) Zhou-Cess

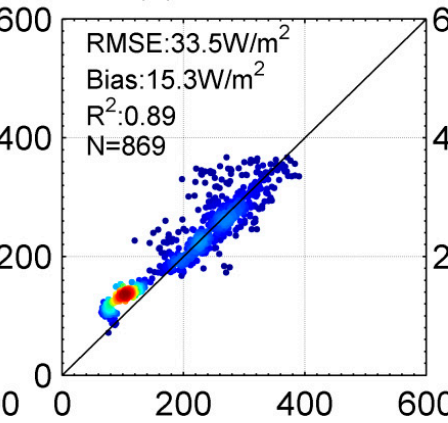

(e) Wang-Liang

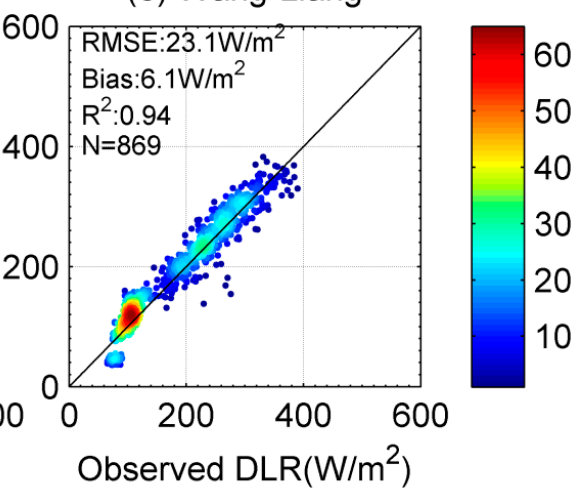

Figure 11. Same as Figure 9 but for the sites in the high-altitude regions. Figures (a) to (e) represent the results from NewParam, Tang-Li, Wang-Liang, Zhou-Cess, and Gupta2010 algorithms. 


\subsubsection{Performance of New Algorithm}

Because MODIS-derived $\delta T_{s, a}$ may have large uncertainties, we used $\delta T_{s, a}$ only at the sites in arid and polar regions and the SGP-C1 site where Ts were largely different from Ta and the uncertainties. Specifically, we used dry grass-only coefficients for the arid sites, and all surfaces-average coefficients for other sites. Table 7 indicates that the new algorithm had good results at most sites with accuracies within $25 \mathrm{~W} / \mathrm{m}^{2}$. The mean RMSEs of DLRs were 20.5, 23.3, and $22.1 \mathrm{~W} / \mathrm{m} 2$ for ordinary, arid, and high-altitude regions, respectively.

As shown in Figure 9a, the new parameterization performed well under most circumstances in ordinary regions but produced some negative errors at the lower DLRs $\left(\leq 200 \mathrm{~W} / \mathrm{m}^{2}\right)$, which were at NSA-C1, and had some positive and negative errors at the higher DLRs $\left(\sim 400 \mathrm{~W} / \mathrm{m}^{2}\right)$, which were at TWP-C1. We further analyzed the error sources by comparing satellite and field measured parameters at NSA-C1 and TWP-C1. Because field measured IWVs were discontinued, only parts of the samples were analyzed. The DLR underestimations of NSA-C1 mainly occurred in the winter season when MODIS IWV had negative errors up to $-50 \%$ compared to field measurements. The other error sources included uncertainty in $\delta T_{s, a}$ and the fact that the algorithm could not accurately simulate DLRs for some polar profiles, as mentioned in Section 3.1. The DLR underestimation and overestimation at TWP-C1 were mainly caused by the uncertainty of the MODIS IWV error (from -1.9 to $2.0 \mathrm{~cm}$ ), whereas uncertainty caused by $\delta T_{s, a}$ was relatively small.

DLR RMSEs were 19.5-26.8 W/m² for the arid sites. Using $\delta T_{s, a}$ obviously improved the results at these sites (not shown), especially during daytime. Slight overestimations appeared at the larger DLRs (Figure 10a), which mainly happened during daytime. Also, slight underestimations during nighttime were found (not shown). We analyzed the $\delta T_{s, a}$ values at sites Huazhaizi (HZZ) and Desert Rock (DRA), and found the in-situ $\delta T_{s, a}$ had large positive values (10 to $20 \mathrm{~K}$ at HZZ and 5 to $20 \mathrm{~K}$ at DRA) during daytime and slightly negative values ( -5 to $0 \mathrm{~K}$ ) during nighttime. However, the ranges of MODIS $\delta T_{s, a}$ errors during daytime and nighttime were -5 to $5 \mathrm{~K}$ and 5 to $10 \mathrm{~K}$ at $\mathrm{HZZ}$ and were -10 to $5 \mathrm{~K}$ (mainly negative errors) and 0 to $5 \mathrm{~K}$ at DRA. Therefore, the retrieved DLRs had larger negative errors during nighttime at $\mathrm{HZZ}$ and larger positive errors during daytime at DRA. We recalculated the DLRs using in-situ $\delta T_{s, a}$ and found the uncertainty caused by $\delta T_{s, a}$ was within $20 \mathrm{~W} / \mathrm{m}^{2}$ at both sites.

DLRs accuracies ranged from 7.8 to $35.7 \mathrm{~W} / \mathrm{m}^{2}$ at the high-altitude sites. As shown in Figure 11a, DLRs had large positive errors at the large DLRs, which mainly occurred at GLEES, and had negative errors at lower DLRs that were in the winter of SPO. Furthermore, some overestimations at Arou (AR) and overestimations and underestimations at FMF were found. The errors at GLEES, AR, and FMF were mainly caused by the uncertainty of IWV. We found MODIS IWV had some values much greater than those on adjacent days during nighttime at AR and GLEES. When the pixels with IWV $\geq 2.1 \mathrm{~cm}$ were removed, the DLR accuracies improved from $6.3 \pm 35.7$ to $-3.2 \pm 25.7 \mathrm{~W} / \mathrm{m}^{2}$ at GLEES. As for the SPO site, the underestimations were caused by IWV uncertainty, the algorithm limitation in polar winter, and strong temperature inversions. The mean relative error of MODIS-derived IWV was $-71.9 \%$, and the thick inversion layer with temperature lapse rate exceeding $-20 \mathrm{~K} / \mathrm{km}$ was frequently found at SPO during winter.

\subsubsection{Comparison with Other Algorithms}

The new algorithm was compared with the four algorithms in Section 2.1. Considering that the coefficients of Wang-Liang algorithm were derived over the North American continent and cannot represent the atmosphere in tropical and Antarctic regions, its coefficients were calibrated at sites DOM, SPO, and TWP-C1 to compare these algorithms equally.

In the ordinary regions, the RMSE of MODIS DLRs from the new algorithm was 1.0 and $1.5 \mathrm{~W} / \mathrm{m}^{2}$ smaller than those from Wang-Liang and Gupta2010 algorithms and was 13.8 and $5.4 \mathrm{~W} / \mathrm{m}^{2}$ smaller than those from Tang-Li and Zhou-Cess algorithms. Though Wang-Liang and Gupta2010 had similar performance to the new algorithm (Figure 9), Gupta2010 had large positive errors at SGP, and 
Wang-Liang slightly underestimated the DLRs at Yingke (YK) and overestimated the DLRs at NSA-C1 (Table 7). For the Zhou-Cess algorithm, the DLRs at the lower end were overestimated, and those at the higher end were underestimated for the DLRs within 200-400 W/m² (at YK and SGP-C1), while the DLRs $\geq 400 \mathrm{~W} / \mathrm{m}^{2}$ (at TWP-C1) were underestimated. Tang-Li significantly overestimated the DLRs at all ranges.

For the sites in arid regions, the RMSE from the new algorithm was slightly larger than those from Zhou-Cess and Gupta2010 $\left(\sim 0.5-1.0 \mathrm{~W} / \mathrm{m}^{2}\right)$, and much smaller than those from the Tang-Li and Wang-Liang algorithms $\left(\sim 8.5-20.3 \mathrm{~W} / \mathrm{m}^{2}\right)$. Though it performed slightly better, Zhou-Cess showed underestimations overall (Figure 10b), whereas Gupta2010 had obvious negative biases at HZZ and SBO (Figure 10c). The Tang-Li algorithm significantly overestimated DLRs, whereas the Wang-Liang algorithm obviously underestimated DLRs (Figure 10d,e). These findings may be because $\delta T_{s, a}$ was not considered by either algorithm. The large positive biases of the Tang-Li algorithm mainly occurred during daytime when large $\delta T_{s, a}$ values were found at these sites. The performance of the Wang-Liang algorithm was consistent with the conclusion of Section 3.1 that DLRs had negative errors for $\delta T_{s, a}<10 \mathrm{~K}$.

In the high-altitude regions, the new algorithm performed slightly better than the Gupta2010, Wang-Liang, and Tang-Li algorithms (with mean RMSE decreased 1.0 to $3.7 \mathrm{~W} / \mathrm{m}^{2}$ ) and much better than the Zhou-Cess algorithm (with mean RMSE decreased $11.4 \mathrm{~W} / \mathrm{m}^{2}$ ). For the DLR within 200-400 W/m² that occurred mainly at sites AR, FMF, and GLEES, the Zhou-Cess and Gupta2010 algorithms had larger positive and negative errors than the new algorithm. Tang-Li slightly overestimated the DLRs overall, while Wang-Liang performed well but had some negative errors (Figure 11). Besides the uncertainty of MODIS IWV, the results of the Gupta2010 and the Zhou-Cess algorithms were also influenced by the uncertainty of MODIS-derived $T_{a}$. For example, the two algorithms greatly underestimated DLRs at Arou, where we found that $T_{a}$ from MODIS was $\sim 10 \mathrm{~K}$ lower than those from the ground measurement. For the lower DLRs in polar regions, Tang-Li overestimated them while the Wang-Liang and the Gupta2010 algorithms underestimated the winter data among them (Figure 11). However, the Zhou-Cess algorithm greatly overestimated the DLRs in polar regions. This may be because the in-situ DLRs and satellite cloud fractions of the two sites were used during the algorithm development [25], and some data of cloudy pixels may not have been discriminated and were fitted as clear sky.

In summary, compared with the Tang-Li and the Wang-Liang algorithms, the new algorithm is based on the Stefan-Boltzmann law and therefore has more reasonable physical meaning. It also performs better over arid regions or other conditions with large $\delta T_{s, a}$ because the difference between air and surface temperature is accounted for in the algorithm. Compared with the Zhou-Cess and the Gupta2010 algorithms, the new algorithm can avoid the underestimations or overestimations in DLR caused by inaccurate air temperature over high-altitude regions.

\subsection{Evaluation of Different Atmospheric Products for DLR Retrievals}

We found the same problem as Li et al. [48] that MODIS's profile lacked lower-atmospheric data at high-altitude sites AR and YK. NCEP data with higher vertical resolution were used and compared with MODIS for the high-altitude sites. In this section, the atmospheric parameters for DLR retrieval, including $T_{a}, I W V, T_{s}$, and atmospheric profiles, were obtained from NCEP, and the other inputs were unchanged.

\subsubsection{Difference between MODIS- and NCEP-derived Atmospheric Parameters}

Figure 12 shows a comparison of MODIS- and NCEP-derived atmospheric profiles at sites AR, GLEES, and SPO. For the AR site, because the surface pressure from MODIS was much smaller than the observed value, the atmospheric information of a thickness $\sim 50 \mathrm{hPa}$ above the surface was missing. Since the surface $T_{a}$ and infrared IWV was obtained from the MODIS atmospheric profile, the information deficiencies in the lower troposphere may have led to the underestimations of $T_{a}$ and 
nighttime IWV. Conversely, the surface pressure from MODIS was $\sim 60 \mathrm{hPa}$ larger than the observed values at the GLEES site, which may have caused IWV overestimation. The surface-level $T_{a}$ that interpolated from NCEP data was closer to observed values than those from MODIS at the two sites. As for SPO, the surface pressure was similar to the observed value, but the $T_{a}$ interpolated from MODIS lowest atmospheric level by assuming a temperature lapse rate of $6.5 \mathrm{~K} / \mathrm{km}$ had a larger error than the NCEP-derived $T_{a}$.
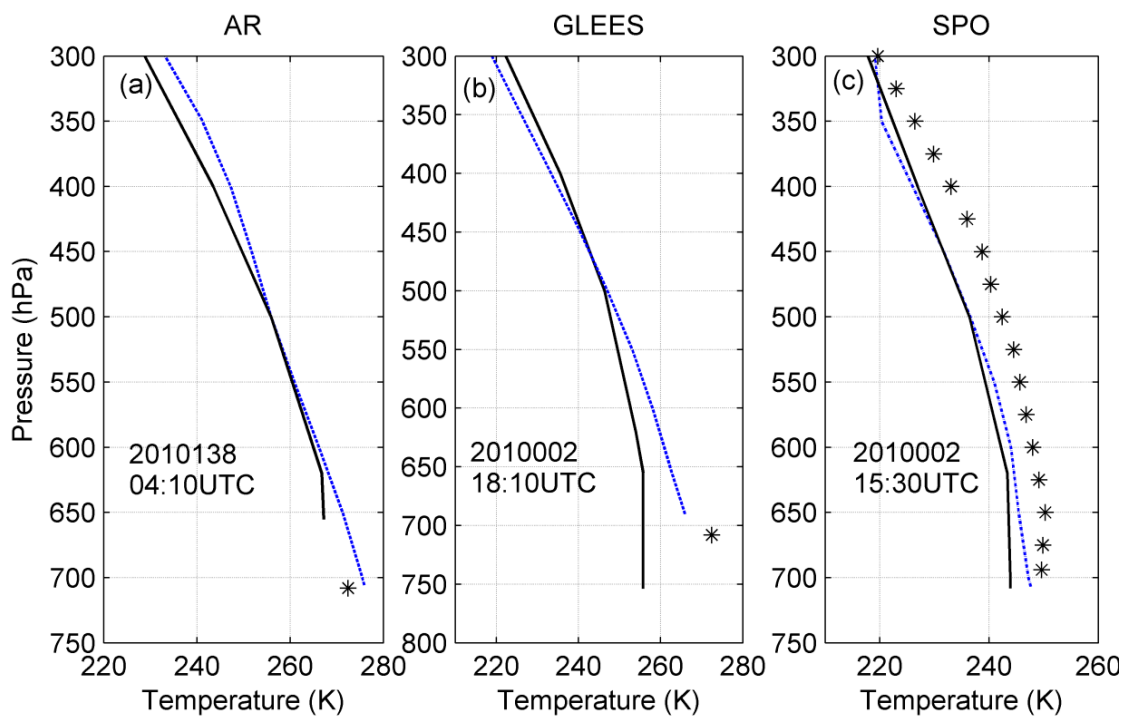

Figure 12. Vertical distribution of air temperatures from the National Centers for Environmental Prediction (NCEP) and MOD07 profiles at sites Arou (AR), US-GLE Wyoming (GLEES), and South Pole (SPO). The solid line, dashed line, and asterisk represent MODIS, NCEP, and field-measured data, respectively.
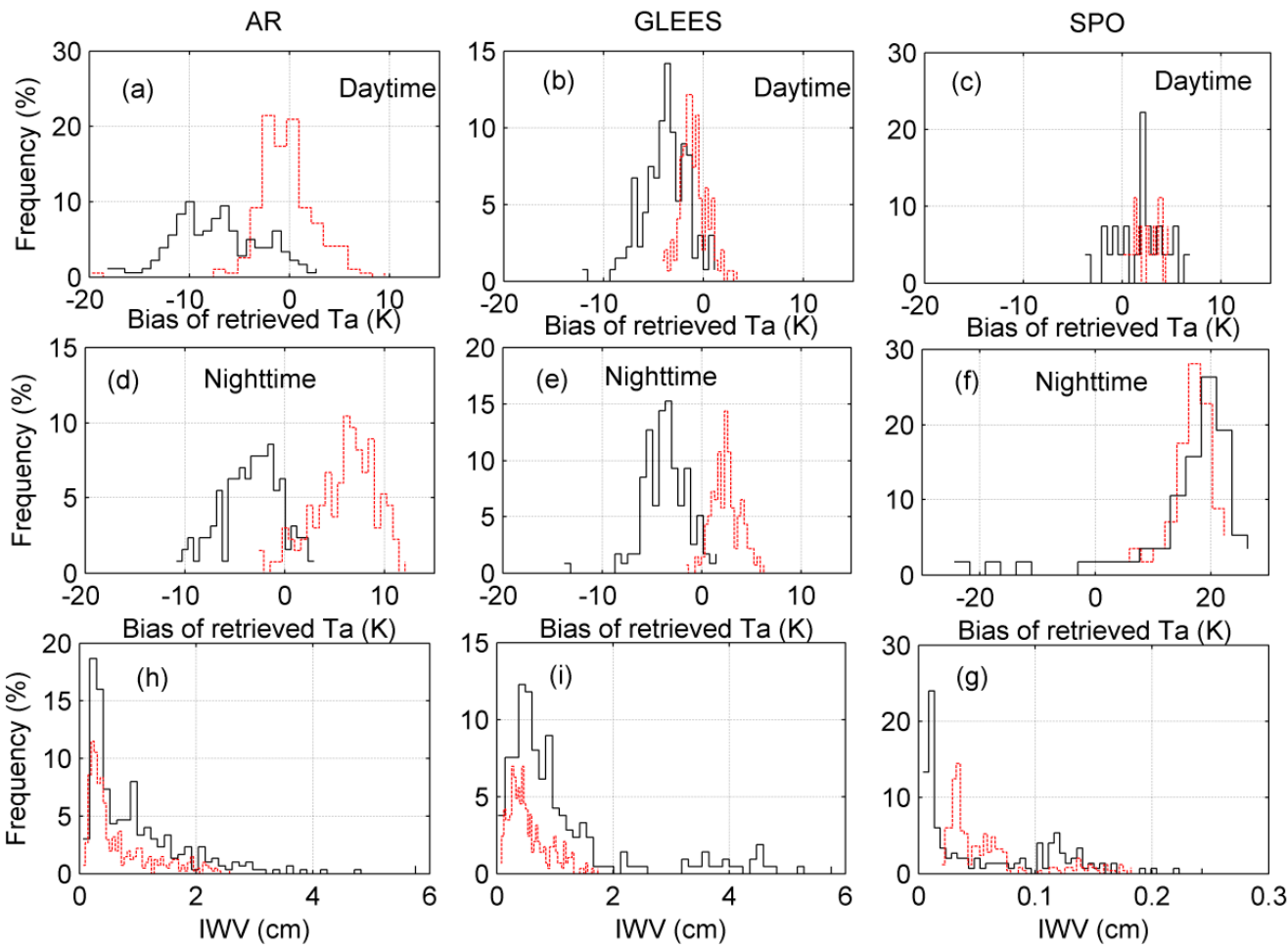

Figure 13. Comparison of MODIS-derived atmospheric parameters with those from NCEP at the sites AR (left column), GLEES (middle column), and SPO (right column). The solid line and dashed line represent parameters from MODIS and NCEP, respectively. 
Figure 13 shows the histograms of IWV and bias in $T_{a}$ from the two products at these sites. MODIS-derived $T_{a}$ had a median bias of about -10 and $-4 \mathrm{~K}$ for daytime and nighttime at AR, while the NCEP-derived $T_{a}$ was better during the daytime. The distribution of bias in $T_{a}$ from NCEP was more centralized toward zero compared to that of MODIS at the GLEES site. The MODIS IWV had some large IWV values at AR and GLEES, which were unreasonable, whereas these very large values were smoothed by NCEP data. For the SPO site, we found the number of underestimated $T_{a}$ from MODIS was deduced, and the IWVs negative biases during winter that were mentioned in Section 4.2 were decreased after using NCEP data compared to those from MODIS.

\subsubsection{Difference between MODIS- and NCEP-derived DLRs}

DLRs at the high-altitude sites were calculated by the NCEP parameters using the new, the Zhou-Cess, and the Gupta2010 algorithms. Table 8 indicates that using NCEP parameters distinctly improved the results, especially for the Gupta2010 and the Zhou-Cess algorithms. The DLR underestimations at SPO during winter and at AR, as well as the overestimations at GLEES, were substantially corrected. DLR RMSEs decreased by 5.5 and $19.1 \mathrm{~W} / \mathrm{m}^{2}$ at AR and GLEES for Zhou-Cess and decreased by 2.4, 19.0 and $6.7 \mathrm{~W} / \mathrm{m}^{2}$ at AR, SPO, and GLEES for Gupta2010. Because only IWV was improved, the new algorithm was less affected by different sources of atmospheric data than the other two algorithms. The DLR RMSEs decreased at SPO and GLEES (3.1 and $\left.7.8 \mathrm{~W} / \mathrm{m}^{2}\right)$ but slightly increased at AR and FMF. Figure 14 displays the scatter points between retrieved and observed DLRs and the distributions of DLR biases from NCEP and MODIS, respectively. Comparing Figure 14 with Figure 11, the dispersed points were diminished for the three algorithms, and the underestimated points at the low DLRs were corrected for Gupta2010. Figure 14d-i indicates that errors from NCEP had narrower distributions than those from MODIS. Furthermore, we compared the two products in other regions and found that using NCEP-derived parameters appreciably improved results of these algorithms under extreme climatic conditions, such as during the winter of NSA-C1 and at site TWP-C1. NCEP data are not recommended for other regions because the coarse resolution causes great uncertainties in atmospheric parameters.

Table 8. Same as Table 7 but for the results in the high-altitude regions. The clear-sky DLRs were estimated using NCEP atmospheric data. The differences between RMSE from NCEP and that from MODIS are displayed in the brackets.

\begin{tabular}{cccccccccc}
\hline \multirow{2}{*}{ Event Label } & \multicolumn{3}{c}{ NewParam } & \multicolumn{3}{c}{ Zhou-Cess } & \multicolumn{3}{c}{ Gupta2010 } \\
\cline { 2 - 10 } & RMSE & Bias & $\mathbf{R}^{\mathbf{2}}$ & RMSE & Bias & $\mathbf{R}^{\mathbf{2}}$ & RMSE & Bias & $\mathbf{R}^{\mathbf{2}}$ \\
\hline AR & $25.2(1.5)$ & 7.0 & 0.78 & $21.6(-5.5)$ & -3.2 & 0.84 & $24.8(-2.4)$ & -15.6 & 0.87 \\
DOM & $7.8(0)$ & 3.3 & 0.63 & $35.1(+0.3)$ & 34.7 & 0.73 & $14.6(+2.2)$ & 13.3 & 0.74 \\
SPO & $12.4(-3.1)$ & -8.4 & 0.88 & $29.4(-0.2)$ & 28.5 & 0.96 & $5.3(-19)$ & 0.5 & 0.96 \\
FMF & $26.8(4.3)$ & -3.4 & 0.77 & $20.2(-3.6)$ & -10.4 & 0.87 & $21.8(+3.9)$ & -14.5 & 0.88 \\
GLEES & $27.9(-7.8)$ & -11.4 & 0.74 & $26.3(-19.1)$ & 2.3 & 0.73 & $27.9(-6.7)$ & -8.4 & 0.71 \\
Mean & $21.3(-0.8)$ & -2.2 & 0.94 & $27.8(-5.7)$ & 10.8 & 0.96 & $20.5(-2.6)$ & -3.1 & 0.96 \\
\hline
\end{tabular}



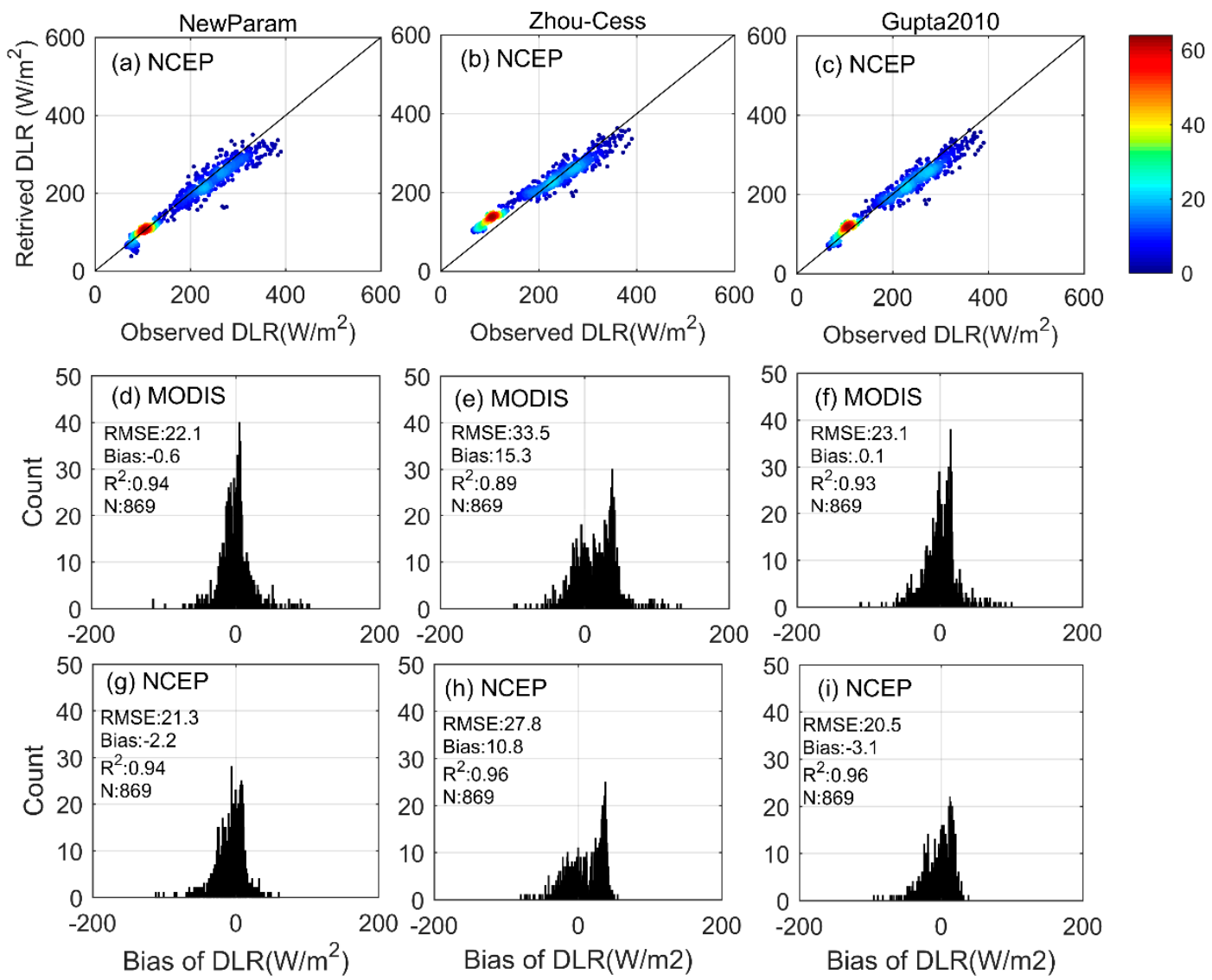

Figure 14. The results of DLRs at the sites in high-altitude regions. Scatter plot between DLRs estimated from NCEP atmospheric parameters and observed DLR are shown in (a-c). Error histograms between observed and retrieved DLRs from MODIS (d-f) and from NCEP $(\mathbf{g}-\mathbf{i})$. Bias was computed as retrieved minus observed values. The left, middle, and right panels represent the results from the new parameterization, the Zhou-Cess, and the Gupta2010 algorithms, respectively.

\section{Conclusions}

In this study, the Yu2013 algorithm that parameterized clear-sky DLR using BT and IWV was improved and extended to MODIS data. The improved parameterization avoids considerable DLR underestimations under high IWV conditions by changing the functional form of water vapor from square-root to logarithmic. An evaluation based on a testing dataset generated from global atmospheric profiles and MODTRAN simulations indicates that the new parameterization was not restricted by sample number and could greatly improve results at large IWV compared with the original parameterization. The total RMSE of DLR decreased by $\sim 1.9$ to $3.1 \mathrm{~W} / \mathrm{m}^{2}$, and DLR accuracy under high IWV $(>3.0 \mathrm{~cm})$ improved by $0.5 \%-16.9 \%$.

Accuracy evaluation using the simulated testing dataset shows that the algorithm gives accuracies between 5.4 and $20.8 \mathrm{~W} / \mathrm{m}^{2}$ when the input parameters are perfectly accurate. A sensitivity analysis indicates that DLR accuracy is greatly affected by uncertainties of IWV, BT, and $\delta T_{s, a}$. DLR error is more sensitive to the error in IWV at large IWVs and at small IWVs at high altitudes, to the error of BT at high-BT conditions, and to the error of $\delta T_{s, a}$ under high-temperature and low-IWV conditions than it is to other conditions. The new algorithm was compared with four state-of-the-art algorithms. The two algorithms parameterized with TOA radiance produced large positive or negative errors, especially for large DLRs when $T_{s}$ was much higher or lower than $T_{a}$. The new algorithm accounted for $\delta T_{s, a}$ and made improvements at high IWV, thereby achieving better results than the two algorithms. The new algorithm also gives slightly better results to the two atmospheric parameter-based algorithms for 
$\mathrm{VZA} \leq 50^{\circ}$, whereas the latter two algorithms would be greatly affected by the uncertainties of IWV and air and surface temperatures in actual applications.

The new algorithm was applied to MODIS Terra data and extensively validated using one year's ground data from 14 stations around the globe. The algorithm produced favorable results at most sites with accuracies within $25 \mathrm{~W} / \mathrm{m}^{2}$. However, the algorithm performed poorly under extreme climatic conditions, such as winter in polar regions with a dry and cold climate and in the tropical western Pacific with a warm and moist climate. The poor performance for these conditions was mainly caused by the uncertainty of MODIS-derived IWV and $\delta T_{s, a}$ and the algorithm limitations under extreme climate. The proposed algorithm had much better results than the TOA radiance-based algorithms in dry-arid regions or other conditions in which $T_{s}$ was substantially different from $T_{a}$ because $\delta T_{s, a}$ was considered. The algorithm performed 1.0 to $11.4 \mathrm{~W} / \mathrm{m}^{2}$ better than atmospheric parameter-based algorithms in high-altitude regions because DLRs from the latter two algorithms were greatly affected by the inaccurate air temperature.

To evaluate the effect of different atmospheric datasets on DLR accuracy, MODIS and NCEP atmospheric products were compared for DLR estimation. The NCEP-derived atmospheric parameters were more accurate than MODIS data in high-altitude regions because the lowest layers from MODIS profiles sometimes were above or below the actual surface there, which caused the underestimations or overestimations of IWV and $T_{a}$. In addition, using NCEP data could avoid the very large positive/negative IWV errors and $T_{a}$ errors from MODIS. Therefore, using NCEP data could clearly improve DLR estimation in such regions, especially for the atmospheric parameter-based algorithms (RMSE decreased by 2.2 to $19.1 \mathrm{~W} / \mathrm{m}^{2}$ ).

The study demonstrates that the new parameterization works well in most situations and overcomes the shortcomings of current TOA radiance-based and atmospheric parameter-based algorithms. In future work, the new algorithm will be applied to geostationary satellite data, such as Meteosat-9/10 and GOES13, to obtain diurnal changes in DLR, whereby acquiring accurate IWV and $\delta T_{s, a}$ is most important during the DLR estimations. Moreover, the algorithm needs further modification to improve performance under extreme climatic conditions.

Author Contributions: S.Y. and X.X. conceived and designed the research; Q.L. supervised and managed the research; H.Z. and L.L. gave a considerable amount of helpful advice on the revised work; S.Y. wrote the article.

Funding: This research was supported by the National Key Research and Development Program (Grant No. 2018YFA0605502) and the National Natural Science Foundation of China (Grant No. 41301392, 41871252).

Acknowledgments: The ECMWF sampled profiles dataset and relevant program were obtained from http: //nwpsaf.eu/deliverables/rtm/profile_datasets.html. The TIGR profiles were obtained from http://ara.abct.lmd. Polytechnique.fr/index.php?page=tigr. The CLAR data were obtained from the author who selected these data from http:// weather.uwyo.edu/upperair/sounding.html. The field measurements of BSRN, ARM, WATER and Ameriflux are available on http:/ / www.bsrn.awi.de/, http:/ /www.arm.gov/, http:/ /westdc.westgis.ac.cn/, and http: / / ameriflux.lbl.gov /. The NCEP data are obtained from http:/ / rda.ucar.edu/datasets/ds083.2/. Thanks Tang Bohui for providing the coefficients of their algorithm.

Conflicts of Interest: The authors declare no conflict of interest.

\section{References}

1. Lee, H.T.; Ellingson, R.G. Development of a nonlinear statistical method for estimating the downward longwave radiation at the surface from satellite observations. J. Atmos. Ocean. Technol. 2002, 19, 1500-1515. [CrossRef]

2. Andrews, T.; Forster, P.M.; Gregory, J.M. A Surface Energy Perspective on Climate Change. J. Clim. 2009, 22, 2557-2570. [CrossRef]

3. Wild, M. Towards global estimates of the surface energy budget. Curr. Clim. Chang. Rep. 2017, 3, 87-97. [CrossRef]

4. Stephens, G.L.; Wild, M.; Stackhouse, P.W.; L'Ecuyer, T.; Kato, S.; Henderson, D.S. The global character of the flux of downward longwave radiation. J. Clim. 2012, 25, 2329-2340. [CrossRef] 
5. Trenberth, K.E.; Fasullo, J.T.; Kiehl, J. Earth's Global Energy Budget. Bull. Am. Meteorol. Soc. 2009, 90, 311-323. [CrossRef]

6. Darnell, W.L.; Gupta, S.K.; Staylor, W.F. Downward Longwave Radiation at the Surface from Satellite Measurements. J. Clim. Appl. Meteor. 1983, 22, 1956-1960. [CrossRef]

7. Rossow, W.B.; Zhang, Y.C. Calculation of surface and top-of-atmosphere radiative fluxes from physical quantities based on ISCCP datasets: 2. Validation and first results. J. Geophys. Res. 1995, 100, 1167-1197. [CrossRef]

8. Charlock, T.P.; Rose, F.G.; Rutan, D.A.; Alberta, T.L.; Kratz, D.P.; Coleman, L.H.; Smith, G.L.; Smith, N.M.; Bess, T.D. Compute Surface and Atmospheric Fluxes (System 5.0). CERES Algorithm Theoretical Basis Doc; ATBD Release 2.2; NASA/RP-1376; 1997; 84p. Available online: https:/ / ceres.larc.nasa.gov/documents / ATBD/ pdf/r2_2/ceres-atbd2.2-s5.0.pdf (accessed on 18 February 2019).

9. Liang, S.L.; Wang, K.C.; Zhang, X.; Wild, M. Review on estimation of land surface radiation and energy budgets from ground measurement, remote sensing and model simulations. IEEE J. Sel. Top. Earth Obs. Remote Sens. 2010, 3, 225-240. [CrossRef]

10. Idso, S.B. A set of equations for full spectrum and 8- to 14-mm and 10.5- to 12.5-mm thermal radiation from cloudless skies. Water Resour. Res. 1981, 17, 295-304. [CrossRef]

11. Prata, A.J. A new long-wave formula for estimating downward clear-sky radiation at the surface. $Q$. J.R. Meteor. Soc. 1996, 122, 1127-1151. [CrossRef]

12. Crawford, T.M.; Duchon, C.E. An improved parameterization for estimating effective atmospheric emissivity for use in calculating daytime downwelling longwave radiation. J. Appl. Meteorol. 1999, 38, 474-480. [CrossRef]

13. Duarte, H.F.; Dias, N.L.; Maggiotto, S.R. Assessing daytime downward longwave radiation estimates for clear and cloudy skies in Southern Brazil. Agric. For. Meteorol. 2006, 139, 171-181. [CrossRef]

14. Schmetz, P.; Schmetz, J.; Raschke, E. Estimation of daytime downward longwave radiation at the surface from satellite and grid point data. Theor. Appl. Climatol. 1986, 37, 136-149. [CrossRef]

15. Tuzet, A. A simple method for estimating downward longwave radiation from surface and satellite data by clear sky. Int. J. Remote Sens. 1990, 11, 125-131. [CrossRef]

16. Trigo, I.F.; Barroso, C.; Viterbo, P.; Freitas, S.C.; Monteiro, I.T. Estimation of downward long-wave radiation at the surface combining remotely sensed data and NWP data. J. Geophys. Res. 2010, 115, D24118. [CrossRef]

17. Ryu, Y.; Kang, S.; Moon, S.K.; Kim, J. Evaluation of land surface radiation balance derived from moderate resolution imaging spectroradiometer (MODIS) over complex terrain and heterogeneous landscape on clear sky days. Agric. For. Meteorol. 2008, 148, 1538-1552. [CrossRef]

18. Bisht, G.; Bras, R.L. Estimation of net radiation from the MODIS data under all sky conditions: Southern Great Plains case study. Remote Sens. Environ. 2010, 114, 1522-1534. [CrossRef]

19. Diak, G.R.; Bland, W.L.; Mecikalski, J.R.; Anderson, M.C. Satellite-based estimates of longwave radiation for agricultural applications. Agric. For. Meteorol. 2000, 103, 349-355. [CrossRef]

20. Naud, C.M.; Miller, J.R.; Landry, C. Using satellites to investigate the sensitivity of longwave downward radiation to water vapor at high elevations. J. Geophys. Res. 2012, 117, D05101. [CrossRef]

21. Gupta, S.K. A parameterization for longwave surface radiation from Sun-synchronous satellite data. J. Clim. 1989, 2, 305-320. [CrossRef]

22. Gupta, S.K.; Kratz, D.P.; Stackhouse, P.W.; Wilber, A.C.; Zhang, T.P.; Sothcott, V.E. Improvement of Surface Longwave Flux Algorithms Used in CERES Processing. J. Appl. Meteor. Climatol. 2010, 49, 1579-1589. [CrossRef]

23. Inamdar, A.K.; Ramanathan, V. On monitoring the atmospheric greenhouse effect from space. Tellus B 1997, 49, 216-230. [CrossRef]

24. Zhou, Y.P.; Cess, R.D. Algorithm development strategies for retrieving the downwelling longwave flux at the Earth's surface. J. Geophys. Res. 2001, 106, 12477-12488. [CrossRef]

25. Zhou, Y.P.; Kratz, D.P.; Wilber, A.C.; Gupta, S.K.; Cess, R.D. An improved algorithm for retrieving surface downwelling longwave radiation from satellite measurements. J. Geophys. Res. 2007, 112, D15102. [CrossRef]

26. Yang, K.; Koike, T.; Stackhouse, P.; Mikovitz, C.; Cox, S.J. An assessment of satellite surface radiation products for highlands with Tibet instrumental data. Geophys. Res. Lett. 2006, 33, L22403. [CrossRef]

27. Gui, S.; Liang, S.L.; Li, L. Evaluation of satellite-estimated surface longwave radiation using ground-based observations. J. Geophys. Res. 2010, 115, D18214. [CrossRef] 
28. Yan, H.R.; Huang, J.P.; Minnis, P.; Wang, T.H.; Bi, J.R. Comparison of CERES surface radiation fluxes with surface observations over Loess Plateau. Remote Sens. Environ. 2011, 115, 1489-1500. [CrossRef]

29. Zhang, Y.C.; Rossow, W.B.; Stackhouse, P.W. Comparison of different global information sources used in surface radiative flux calculation: Radiative properties of the near-surface atmosphere. J. Geophys. Res. 2006, 111, D13106. [CrossRef]

30. Tang, B.; Li, Z.L. Estimation of instantaneous net surface longwave radiation from MODIS cloud-free data. Remote Sens. Environ. 2008, 112, 3482-3492. [CrossRef]

31. Wang, W.H.; Liang, S.L. Estimation of high-spatial resolution clear-sky longwave downward and net radiation over land surfaces from MODIS data. Remote Sens. Environ. 2009, 113, 745-754. [CrossRef]

32. Wang, T.X.; Yan, G.J.; Chen, L. Consistent retrieval methods to estimate land surface shortwave and longwave radiative flux components under clear-sky conditions. Remote Sens. Environ. 2012, 124, 61-71. [CrossRef]

33. Wang, J.; Tang, B.H.; Zhang, X.Y.; Wu, H.; Li, Z.L. Estimation of Surface Longwave Radiation over the Tibetan Plateau Region Using MODIS Data for Cloud-Free Skies. IEEE J. Sel. Top. Earth Obs. Remote Sens. 2014, 7, 3695-3703. [CrossRef]

34. Cheng, J.; Liang, S.; Wang, W.; Guo, Y. An efficient hybrid method for estimating clear-sky surface downward longwave radiation from MODIS data. J. Geophys. Res. 2017, 122. [CrossRef]

35. Wang, W.H.; Liang, S.L. A Method for Estimating Clear-Sky Instantaneous Land-Surface Longwave Radiation with GOES Sounder and GOES-R ABI Data. IEEE Geosci. Remote Sens. Lett. 2010, 7, 708-712. [CrossRef]

36. Yu, S.S.; Xin, X.Z.; Liu, Q.H. Estimation of clear-sky longwave downward radiation from HJ-1B thermal data. Sci. China Earth Sci. 2013, 56, 829-842. [CrossRef]

37. Wielicki, B.A.; Barkstrom, B.R.; Harrison, E.F.; Lee, R.B., III; Smith, G.L.; Cooper, J.E. Clouds and the Earth's Radiant Energy System (CERES): An earth observation system experiment. Bull. Am. Meteorol. Soc. 1996, 77, 853-868. [CrossRef]

38. Berk, A.; Anderson, G.P.; Acharya, P.K.; Chetwynd, J.H.; Bernstein, L.S.; Shettle, E.P.; Matthew, M.W.; Adler-Goldenet, S.M. MODTRAN4 User's Manual; Air Force Research Laboratory, Space Vehicles Directorate, and Air Force Materiel Command: Hanscom AFB, MA, USA, 1999; pp. 1-99.

39. Chevallier, F.; Chédin, A.; Chéruy, F.; Morcrette, J.-J. TIGR like atmospheric profile databases for accurate radiative flux measurements. Q. J. R. Meteor. Soc. 2000, 126, 777-785. [CrossRef]

40. Chevallier, F. Sampled Databases of 60-Level Atmospheric Profiles from the ECMWF Analyses. EUMETSAT/ECMWF SAF Programme, Research Report No. 4. 2001. Available online: https:/ / nwpsaf.eu/ downloads/profiles/profiles_60L.pdf?8447b5\&8447b5 (accessed on 18 February 2019).

41. Galve, J.M.; Coll, C.; Caselles, V.; Valor, E. An atmospheric radiosounding database for generating land surface temperature algorithms. IEEE Trans. Geosci. Remote Sens. 2008, 46, 1547-1557. [CrossRef]

42. Raddatz, R.L.; Asplin, M.G.; Papakyriakou, T.; Candlish, L.M.; Galley, R.J.; Else, B.; Barber, D.G. All-Sky Downwelling Longwave Radiation and Atmospheric-Column Water Vapour and Temperature over the Western Maritime Arctic. Atmos. Ocean 2013, 51, 145-152. [CrossRef]

43. Ackerman, S.; Frey, R.; Strabala, K.; Liu, Y.H.; Gumley, L.; Baum, B.; Menzel, P. Discriminating Clear-Sky from cloud with MODIS: Algorithm Theoretical Basis Document (MOD35). Cooperative Institute for Meteorological Satellite Studies, University of Wisconsin-Madison, 2010. Available online: https: / / modisatmosphere.gsfc.nasa.gov/documentation/atbds-plans-guides (accessed on 18 February 2019).

44. Gao, B.C.; Kaufman, Y.J. The MODIS Near-IR Water Vapor Algorithm: Algorithm Technical Background Document (MOD05). Climate and Radiation Branch, NASA Goddard Space Flight Center, 1998. Available online: https:/ / modis-atmosphere.gsfc.nasa.gov/documentation/atbds-plans-guides (accessed on 18 February 2019).

45. Gao, B.C.; Kaufman, Y.J. Water vapor retrievals using Moderate Resolution Imaging Spectroradiometer (MODIS) near-infrared channels. J. Geophys. Res. 2003, 108, 4389. [CrossRef]

46. Borbas, E.E.; Seemann, S.W.; Kern, A.; Moy, L.; Li, J.; Menzel, W.P.; Gumley, L.E. MODIS Atmospheric Profile Retrieval, Algorithm Theoretical Basis Document, University of Wisconsin Madison. 2011; Version 7. Available online: https: / modis-atmosphere.gsfc.nasa.gov/documentation/atbds-plans-guides (accessed on 18 February 2019).

47. Lee, H.T.; Laszlo, I.; Gruber, A. ABI Earth Radiation Budget-Downward Longwave Radiation: Surface (DLR); Version 2.0; NOAA Nesdis Center for Satellite Applications and Research, Algorithm Theoretical Basis Document; National Oceanic and Atmospheric Administration: Washington, DC, USA, 2010. 
48. Li, H.; Liu, Q.H.; Du, Y.M.; Jiang, J.X.; Wang, H.S. Evaluation of the NCEP and MODIS Atmospheric Products for Single Channel Land Surface Temperature Retrieval with Ground Measurements: A Case Study of HJ-1B IRS Data. IEEE J. Sel. Top. Earth Obs. Remote Sens. 2013, 6, 1399-1408. [CrossRef]

49. Li, X.; Li, X.W.; Li, Z.Y.; Ma, M.; Wang, J.; Xiao, Q.; Liu, Q.; Che, T.; Chen, E.; Yan, G.; et al. Watershed Allied Telemetry Experimental Research. J. Geophys. Res. 2009, 114, D22103. [CrossRef]

50. Stoffel, T. Solar Infrared Radiation Station (SIRS) Handbook. 7 July 2005. Available online: http: / / www.arm. gov/publications/tech_reports/handbooks/sirs_handbook.pdf (accessed on 18 February 2019).

51. Stoffel, T. ARM Pyrgeometer Calibrations \& Field Measurements: Information Regarding the Data Restriction Notice. 7 December 2005. Available online: http:/ /www.arm.gov/publications/tech_reports/arm-05-111. pdf (accessed on 18 February 2019).

52. Ohmura, A.; Dutton, E.G.; Forgan, B.; Fröhlich, C.; Gilgen, H.; Hegner, H.; Heimo, A.; König-Langlo, G.; McArthur, B.; Philipona, R.; et al. Baseline surface radiation network (BSRN/WCRP): New precision radiometry for climate research. Bull. Am. Met. Soc. 1998, 79, 2115-2136. [CrossRef]

53. Wang, K.; Dickinson, R.E. Global atmospheric downward longwave radiation at the surface from ground-based observations, satellite retrievals, and reanalyses. Rev. Geophys. 2013, 51, 150-185. [CrossRef]

54. Town, M.S.; Walden, V.P.; Warren, S.G. Cloud cover over the South Pole from visual observations, satellite retrievals, and surface-based infrared radiation measurements. J. Clim. 2007, 20, 544-559. [CrossRef]

(C) 2019 by the authors. Licensee MDPI, Basel, Switzerland. This article is an open access article distributed under the terms and conditions of the Creative Commons Attribution (CC BY) license (http://creativecommons.org/licenses/by/4.0/). 